Supporting Information

\title{
Tailoring Electronic and Optical Properties of MXenes through Forming Solid Solutions
}

Meikang Han, ${ }^{1,2} \uparrow$ Kathleen Maleski,,${ }^{1,2} \uparrow$ Christopher Eugene Shuck,,${ }^{1,2} \dagger$ Yizhou Yang, ${ }^{2}$ James T. Glazar, ${ }^{3}$ Alexandre C. Foucher, ${ }^{3}$ Kanit Hantanasirisakul, ${ }^{1,2}$ Asia Sarycheva, ${ }^{1,2}$ Nathan C. Frey, ${ }^{3}$ Steven J. May, ${ }^{2}$ Vivek B. Shenoy, ${ }^{3}$ Eric A. Stach, ${ }^{3}$ and Yury Gogotsi ${ }^{1,2 *}$

${ }^{1}$ A. J. Drexel Nanomaterials Institute, Drexel University, Philadelphia, PA 19104, USA

${ }^{2}$ Department of Materials Science and Engineering, Drexel University, Philadelphia, PA 19104, USA

${ }^{3}$ Department of Materials Science and Engineering, University of Pennsylvania, Philadelphia, PA 19104, USA

*Correspondence to Prof. Yury Gogotsi (Y.G.). Email: gogotsi@drexel.edu

$\dagger$ These authors contributed equally to this work.

\section{Table of Contents}

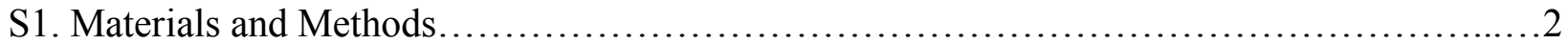

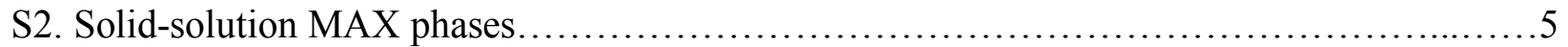

Figure S1. XRD patterns of as-synthesized solid-solution MAX phases........................

Figure S2. Lattice parameters determined for the solid-solution MAX phases................... 7

Figure S3. Normalized atomic ratios of two metal elements in solid-solution MXenes...............8

Figure S4. STEM images of $\mathrm{Ti}_{0.8} \mathrm{Nb}_{1.2} \mathrm{CT}_{x}$ MXene flake.................................. 8

Figure S5. STEM images of $\mathrm{V}_{0.8} \mathrm{Nb}_{1.2} \mathrm{CT}_{x}$ MXene flake...................................

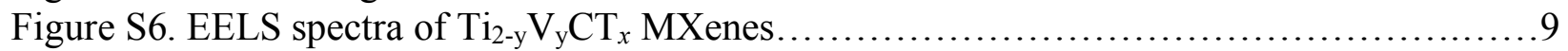

Figure S7. Dynamic light scattering intensity distribution of $\mathrm{Ti}_{2-\mathrm{y}} \mathrm{V}_{\mathrm{y}} \mathrm{CT}_{x}$ flakes...............10

Figure S8. Digital images of freestanding solid-solution MXene films....................... 10

Figure S9. XPS spectra of a $\mathrm{Ti}_{1.2} \mathrm{Nb}_{0.8} \mathrm{CT}_{x}$ free-standing film............................... 11

Figure S10. XPS spectra of a $\mathrm{Ti}_{1.2} \mathrm{~V}_{0.8} \mathrm{CT}_{x}$ free-standing film.................................

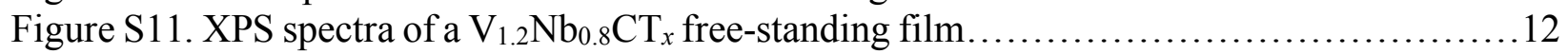

Figure S12. Formation energies for solid solutions of $\mathrm{M}_{2-\mathrm{y}} \mathrm{M}_{\mathrm{y}} \mathrm{C}$ MXenes....................... 13

Figure S13. ECI energies for the cluster expansions of $\mathrm{M}_{2-\mathrm{y}} \mathrm{M}_{\mathrm{y}} \mathrm{C}$ MXenes...................... 14

Figure S14. Goodness-of-fit plots for the three $\mathrm{M}_{2-\mathrm{y}} \mathrm{M}_{\mathrm{y}} \mathrm{C}$ MXene systems.................... 14

Figure S15. The computed electron density of states of $\mathrm{Ti}_{2-\mathrm{y}} \mathrm{V}_{\mathrm{y}} \mathrm{C}$ and $\mathrm{V}_{2-\mathrm{y}} \mathrm{Nb}_{\mathrm{y}} \mathrm{C}$ MXenes........15

Figure S16. XAS analysis of solid-solution MXenes..................................... 16

Figure $\mathrm{S} 17 . \mathrm{Ti}_{2} \mathrm{C}, \mathrm{TiVC}$, and $\mathrm{TiNbC}$ ground state structures................................ 16

Figure S18. Normalized UV-vis spectra of pure $\mathrm{M}_{2} \mathrm{CT}_{x}$ MXenes.......................... 17

Table S1. The synthesized conditions of solid-solution $\mathrm{M}_{2-\mathrm{y}} \mathrm{M}_{\mathrm{y}} \mathrm{CT}_{\mathrm{x}}$ MXenes..................

Table S2. The measured element amount of solid-solution $\mathrm{M}_{2-\mathrm{y}}^{\prime} \mathrm{M}_{\mathrm{y}} \mathrm{CT}_{x} \mathrm{MXenes} \mathrm{from} \mathrm{XPS.....12}$

Table S3. Normalized stoichiometric ratios of solid-solution $\mathrm{M}_{2-\mathrm{y}} \mathrm{M}_{\mathrm{y}} \mathrm{CT}_{x}$ MXenes.............13

Table S4. Electrical conductivities for O- and F-terminated MXenes.......................... 17

Table S5. The parent crystal structure used for cluster expansion........................... 18

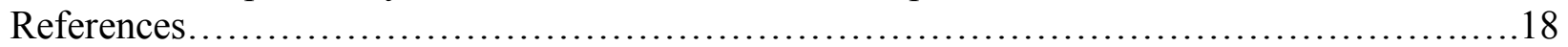




\section{S1. Materials and Methods}

Synthesis of $M_{2-y}^{\prime} M_{\underline{y}}{ }_{\underline{y}}$ AlC MAX phases

Three kinds of solid-solution $\mathrm{M}_{2-\mathrm{y}} \mathrm{M}_{\mathrm{y}} \mathrm{AlC} \mathrm{MAX}$ phases were synthesized, including $\mathrm{Ti}_{2}$ ${ }_{y} \mathrm{Nb}_{\mathrm{y}} \mathrm{AlC}, \mathrm{V}_{2-\mathrm{y}} \mathrm{Nb}_{\mathrm{y}} \mathrm{AlC}$ and $\mathrm{Ti}_{2-\mathrm{y}} \mathrm{V}_{\mathrm{y}} \mathrm{AlC}(\mathrm{y}=0,0.4,0.8,1.2,1.6$, and 2$)$. Initially, the precursor powders, Ti (99.5\%, -325 mesh, Alfa Aesar), V (99.5\%, -325 mesh, Alfa Aesar), Nb (99.99\%, 325 mesh, Beantown Chemical), Al (99.5\%, -325 mesh, Alfa Aesar), and graphite (99\%, -325 mesh, Alfa Aesar) were ball milled in the following atomic ratios: 2-y : y : $1.1: 0.9$, where y is 0 , $0.4,0.8,1.2,1.6$, and 2 . These ratios correspond to the following $\mathrm{M}_{2-\mathrm{y}}^{\prime} \mathrm{M}_{\mathrm{y}}{ }_{\mathrm{AlC}} \mathrm{MAX}$ phases: $\mathrm{M}_{2}{ }_{2} \mathrm{AlC}, \mathrm{M}_{1.6}^{\prime} \mathrm{M}_{0.4} \mathrm{AlC}, \mathrm{M}_{1.2}^{\prime} \mathrm{M}_{0.8} \mathrm{AlC}, \mathrm{M}_{0.8}^{\prime} \mathrm{M}_{1.2} \mathrm{AlC}, \mathrm{M}_{0.4}^{\prime} \mathrm{M}_{1.6} \mathrm{AlC}$, and $\mathrm{M}_{2}{ }_{2} \mathrm{AlC}$, where $\mathrm{M}^{\prime}$ and $\mathrm{M}$ " are any two of $\mathrm{Ti}, \mathrm{V}$, and $\mathrm{Nb}$. Typically, $7 \mathrm{~g}$ of each powder mixture was placed into ceramic crucibles and was moved into a Carbolite furnace. The furnace was heated at $3{ }^{\circ} \mathrm{C} / \mathrm{min}$ to $1550{ }^{\circ} \mathrm{C}$. The furnace was held at this temperature for $2 \mathrm{~h}$, and then was cooled to room temperature at a rate of $3{ }^{\circ} \mathrm{C} / \mathrm{min}$. The powders were ground in a mortar and pestle, then sieved to below $125 \mu \mathrm{m}$.

\section{Synthesis of $M_{2-y}^{\prime} \underline{M_{2}^{\prime \prime}} \underline{\underline{C}} \underline{\underline{x}} \underline{\underline{M} \text { Xenes }}$}

Each MXene in this study was topochemically synthesized from a parent MAX phase precursor with a general formula of $\mathrm{M}_{2-y} \mathrm{M}_{\mathrm{y}} \mathrm{AlC}$. Due to different MXenes having different etching parameters, conditions were varied for each phase and coupled binary system. The synthesized conditions were listed as shown in Table S1.

A. $T i_{2-y} N b_{y} C T_{x}$

For $\mathrm{Ti}_{2-\mathrm{y}} \mathrm{Nb}_{\mathrm{y}} \mathrm{CT}_{\mathrm{x}}(\mathrm{y}=0.4,0.8,1.2$, and 1.6$), \mathrm{LiF}$ and $\mathrm{HCl}(36.5-38 \%$, Fisher Chemical) were chosen as the etchants. Typically, $15 \mathrm{~mL}$ of $\mathrm{HCl}, 1.5 \mathrm{~g}$ of $\mathrm{LiF}$ and $5 \mathrm{~mL}$ of deionized (DI) water were mixed firstly. After that, $1 \mathrm{~g}$ of $\mathrm{Ti}_{2-\mathrm{y}} \mathrm{Nb}_{\mathrm{y}} \mathrm{AlC}$ powder was added into the solution, and then the mixture kept stirring for $48 \mathrm{~h}$ at $35^{\circ} \mathrm{C}$. After the reaction, the solution was washed with DI water using centrifugation at $3500 \mathrm{rpm}$ for $3 \mathrm{~min}$. This washing process was repeated until the supernatant became black. The sediment was re-dispersed with $50 \mathrm{~mL}$ of deionized water and centrifuged at $3500 \mathrm{rpm}$ for $30 \mathrm{~min}$. When sonication was employed, $30 \mathrm{~min}$ of bath sonication $(40 \mathrm{kHz})$ was conducted, followed by $10 \mathrm{~min}$ of centrifugation at $3500 \mathrm{rpm}$ to isolate multilayered or non-exfoliated material. The supernatant after centrifugation (no sonic or sonic) was used for analysis.

For $\mathrm{Ti}_{2} \mathrm{CT}_{\mathrm{x}}$, the synthesized process is the same as $\mathrm{Ti}_{2-\mathrm{y}} \mathrm{Nb}_{\mathrm{y}} \mathrm{CT}_{\mathrm{x}}$, except that the etching time is $24 \mathrm{~h}$.

B. $T i_{2-y} V_{y} C T_{x}$

For $\mathrm{Ti}_{2-\mathrm{y}} \mathrm{V}_{\mathrm{y}} \mathrm{CT}_{\mathrm{x}}(\mathrm{y}=0.4,0.8,1.2$, and 1.6), different HF solutions were chosen to keep the sample synthesis at $24 \mathrm{~h}$. For $\mathrm{Ti}_{0.4} \mathrm{~V}_{1.6} \mathrm{CT}$, $50 \mathrm{wt} . \% \mathrm{HF}$ was used, $\mathrm{Ti}_{0.8} \mathrm{~V}_{1.2} \mathrm{CT}_{x}$ and $\mathrm{Ti}_{1.2} \mathrm{~V}_{0.8} \mathrm{CT}_{x} 30$ wt. \% HF was used, and for $\mathrm{Ti}_{1.6} \mathrm{~V}_{0.4} \mathrm{CT}_{x}$ a $10 \mathrm{wt}$. \% HF solution was used. In all cases, $1 \mathrm{~g}$ of the MAX powder was added to $20 \mathrm{~mL}$ of the etching solution slowly over the course of a few minutes while stirring in an ice bath to prevent overheating. The mixture reacted for $24 \mathrm{~h}$ at $35^{\circ} \mathrm{C}$. After the reaction, the reacted solution was washed with DI water through centrifugation ( $3500 \mathrm{rpm}, 5$ min) several times until the $\mathrm{pH}$ value is $>6$. The centrifuged sediment was intercalated using tetramethylammonium hydroxide (TMAOH, 25 wt. \% in water, Sigma Aldrich). Briefly, $750 \mathrm{mg}$ of multilayered powder was added to $20 \mathrm{~mL}$ of $2.5 \mathrm{wt}$ \% TMAOH. The solution was stirred at $300 \mathrm{rpm}$ for $12 \mathrm{~h}$ at room temperature. Then, the solution was brought to neutral $\mathrm{pH}$ by washing 
through centrifugation $(50 \mathrm{~mL}, 10000 \mathrm{rpm}, 20 \mathrm{~min})$ the supernatant was decanted. The sediment was re-dispersed with $50 \mathrm{~mL}$ of deionized water and centrifuged at $3500 \mathrm{rpm}$ for $10 \mathrm{~min}$. When sonication was employed, $30 \mathrm{~min}$ of bath sonication $(40 \mathrm{kHz})$ was conducted, followed by $30 \mathrm{~min}$ of centrifugation at $3500 \mathrm{rpm}$ to isolate multilayered or non-exfoliated material. The supernatant after centrifugation was used for analysis.

C. $V_{2-y} N b_{y} C T_{x}$

For $\mathrm{V}_{2-\mathrm{y}} \mathrm{Nb}_{\mathrm{y}} \mathrm{CT}_{x}(\mathrm{y}=0,0.4,0.8,1.2,1.6$, and 2$), 50 \mathrm{wt} . \% \mathrm{HF}$ etchant solution was chosen as a starting point. Specifically, $1 \mathrm{~g}$ of $\mathrm{V}_{2-\mathrm{y}} \mathrm{Nb}_{\mathrm{y}} \mathrm{AlC}$ powder was added to $20 \mathrm{~mL} 50 \mathrm{wt}$ \% $\mathrm{HF}$ solution slowly over the course of a few minutes while stirring in an ice bath to prevent overheating. The mixture reacted for $48 \mathrm{~h}$ at $35{ }^{\circ} \mathrm{C}$. After the reaction, the reacted solution was washed with DI water through centrifugation $(3500 \mathrm{rpm}, 3 \mathrm{~min})$ several times until the $\mathrm{pH}$ value is $>6$. The centrifuged sediment was intercalated using TMAOH. Briefly, $750 \mathrm{mg}$ of multilayered powder was added to $20 \mathrm{~mL}$ of $2.5 \mathrm{wt}$. \% TMAOH. The solution was stirred at $300 \mathrm{rpm}$ for $12 \mathrm{~h}$ at room temperature. The washing procedures to obtain colloidal solutions were the same as $\mathrm{Ti}_{2-\mathrm{y}} \mathrm{V}_{\mathrm{y}} \mathrm{CT}_{x}$.

Concentration of the as-prepared solutions was found by vacuum filtering known volumes of liquids (e.g., 10 or $15 \mathrm{~mL}$ ) over a Celgard membrane with a thickness of $25 \mu \mathrm{m}$ (3501 Coated PP, Celgard LLC). After drying at ambient temperature, the freestanding films were removed from the membrane and stored in a desiccator.

Table S1. The synthesized conditions of solid-solution $\mathrm{M}_{2-\mathrm{y}} \mathrm{M}_{\mathrm{y}} \mathrm{CT}_{\mathrm{x}} \mathrm{MXenes}$.

\begin{tabular}{ccccc}
\hline MXene & Etching reagent & $\begin{array}{c}\text { Etching } \\
\text { temperature } \\
\left({ }^{\circ} \mathrm{C}\right)\end{array}$ & $\begin{array}{c}\text { Etching time } \\
(\mathrm{h})\end{array}$ & $\begin{array}{c}\text { Delamination } \\
\text { reagent }\end{array}$ \\
\hline $\mathrm{Ti}_{2} \mathrm{CT}_{x}$ & $\mathrm{HCl}, \mathrm{LiF}$ & $\mathrm{RT}$ & 24 & $/$ \\
$\mathrm{V}_{2} \mathrm{CT}_{x}$ & $\mathrm{HF}$ & 35 & 48 & TMAOH \\
$\mathrm{Nb}_{2} \mathrm{CT}_{x}$ & $\mathrm{HF}$ & 35 & 48 & TMAOH \\
$* \mathrm{Ti}_{2-\mathrm{y}} \mathrm{Nb}_{\mathrm{y}} \mathrm{CT}_{x}$ & $\mathrm{HCl}, \mathrm{LiF}$ & 35 & 48 & $/$ \\
$* \mathrm{Ti}_{2-\mathrm{y}} \mathrm{V}_{\mathrm{y}} \mathrm{CT}_{x}$ & $\mathrm{HF}$ & 35 & 24 & $\mathrm{TMAOH}$ \\
$* \mathrm{~V}_{2-\mathrm{y}} \mathrm{Nb}_{\mathrm{y}} \mathrm{CT}_{x}$ & $\mathrm{HF}$ & 35 & 48 & $\mathrm{TMAOH}$ \\
\hline
\end{tabular}

$* \mathrm{y}=0.4,0.8,1.2$, and 1.6 .

\section{Characterization}

An aberration-corrected JEOL NEOARM operating at $200 \mathrm{kV}$ in scanning transmission electron microscopy (STEM) mode was used to observe MXene flakes. Energy-dispersive X-ray spectroscopy (EDS) data were analyzed with GMS, a software provided by Gatan Inc. Electron energy loss spectroscopy (EELS) was performed with an UltraScan Camera, also provided by Gatan. The condenser lens aperture was $40 \mu \mathrm{m}$ with a camera length of $4 \mathrm{~cm}$ for imaging and 2 $\mathrm{cm}$ for EELS data collection. The probe current of the scanning beam was $120 \mathrm{pA}$ and the energy resolution for EELS study was $0.1 \mathrm{eV}$ per channel. For TEM analysis, the diluted MXene suspensions in distilled water were deposited on lacey carbon films on copper grids manufactured by Electron Microscopy Science. Energy dispersive X-ray spectroscopy (EDS) was conducted in a focused ion beam/scanning electron microscopy (Strata DB235, FEI). Each spectrum was collected at $15 \mathrm{kV}$ with 60 second live time. For each MXene film, five spots were collected at different locations on the film. In all cases, the collected spectra contained more than 50,000 counts. X-ray diffraction (XRD) was conducted on the MAX powders and delaminated 
free-standing films using a Rigaku SmartLab (Tokyo, Japan) operating at $40 \mathrm{kV} / 30 \mathrm{~mA}$ with $\mathrm{Cu}$ $\mathrm{K} \alpha$ radiation. The scan range was from $5-90^{\circ}(2 \theta)$, with a step-scan of $0.02^{\circ}$ and a holding time of $1 \mathrm{~s}$. Rietveld refinement was carried out to evaluate the $a$ and $c$ lattice parameters (LPs), and overall crystal structure using GSAS-II. ${ }^{1}$ Raman spectra were obtained with an inverted reflection mode Renishaw $(2008$, Gloucestershire, UK) instrument, equipped with $63 \times(\mathrm{NA}=0.7)$ objectives and a diffraction-based room-temperature spectrometer. The laser line used was $514 \mathrm{~nm}$ and the laser power was kept around $0.1 \mathrm{~mW}$. Baseline was subtracted from the spectra. Film thickness was determined by micrometer measurement (Mittotoyo Digital Micrometer). UV-visible spectroscopy was performed on dilute solutions of the as-prepared solutions from 200 to $1000 \mathrm{~nm}$ (Evolution 201, Thermo Scientific) using a $10 \mathrm{~mm}$ path length quartz cuvette. Dynamic light scattering (DLS) was performed using a Zetasizer (Nano ZS, Malvern Instruments, USA) to measure the size distribution of flakes. The electrical conductivity of freestanding films was measured using the 4-point probe instrument (ResTest, Jandel Engineering Ltd., Bedfordshire, U.K.), with probe distance of $1 \mathrm{~mm}$. An average value was taken from 3 points across the film. Chemical compositions were determined with X-ray photoelectron spectroscopy (XPS). XPS data were collected by a spectrometer (Physical Electronics, Versa Probe 5000, MN) using a monochromatic Al K $\alpha$ X-ray source with $200 \mu \mathrm{m}$ spot size. Charge neutralization was performed using a dual-beam charge neutralizer. The sample was sputtered with $\mathrm{Ar}$ ions $(2 \mathrm{kV}, 2 \mu \mathrm{A})$ for 2 min inside the chamber. The dependence of resistivity on temperature was measured with a Quantum Design EverCool II Physical Property Measurement System (PPMS). Freestanding solid-solution MXene films were wired into a four-point probe geometry with silver paint. The data from 300 to $10 \mathrm{~K}$ were recorded in a low pressure of helium ( $<5$ Torr). Soft X-ray absorption spectroscopy (XAS) was performed at the Advanced Photon Source beamline 4-ID-C at Argonne National Laboratory. Room temperature total electron yield mode $L$-edge spectra were collected under ultra-high vacuum for all three transition metals, including Ti (450-480 eV), V (510-530 $\mathrm{eV}$ ), and $\mathrm{Nb}(2350-2510 \mathrm{eV}$ ). Spectra shown in Figure S16a-c were normalized to a 0 (pre-edge) to 1 (post-edge) edge jump, which was simulated by sum of two arctan functions. The branching ratios are calculated as $\frac{\int I\left[L_{3}\right]}{\int\left(I\left[L_{3}\right]+I\left[L_{2}\right]\right)} d E$, where $I$ is the normalized XAS intensity.

\section{Density Functional Theory (DFT) Calculations}

DFT calculations were performed using the Vienna Ab initio Simulation Package (VASP) software with the PBE exchange-correlation functional and projector augmented wave (PAW) pseudopotentials..$^{2-6}$ A cutoff energy of $500 \mathrm{eV}$ was used with a $16 \times 16 \times 1 k$-point grid for unit cells of the same size as the primitive non-alloyed cell (Figure S12). All $k$-point grids were automatically rescaled to maintain a constant $k$-point density among solid-solution structures of different sizes. Geometric relaxations were performed until forces on each atom were less than $0.01 \mathrm{eV} / \AA$. Detailed density of state calculations were performed on the lowest energy ground state structures using a finer $32 \times 32 \times 1 k$-point grid.

We constructed thermodynamically stable solid-solution MXenes of $\mathrm{Ti}_{2-\mathrm{y}} \mathrm{Nb}_{\mathrm{y}} \mathrm{C}, \mathrm{V}_{2-\mathrm{y}} \mathrm{Nb}_{\mathrm{y}} \mathrm{C}$, and $\mathrm{Ti}_{2-\mathrm{y}} \mathrm{V}_{\mathrm{y}} \mathrm{C}$ systems using the cluster expansion formalism as implemented in the MIT Ab-Initio Phase Stability (MAPS) code. ${ }^{7}$ Cluster expansion fits an Ising-like model to DFT energy data in order to predict the formation energies of solid solutions. The generalized model is given by 


$$
E(\sigma)=\sum_{\alpha} m_{\alpha} J_{\alpha}\left\langle\prod_{i \in \alpha^{\prime}} \sigma_{i}\right\rangle
$$

where $E(\sigma)$ is the formation energy of a solid-solution configuration $\sigma, m_{\alpha}$ is the symmetrydetermined multiplicity of a cluster $\alpha, J_{\alpha}$ is the effective cluster interaction energy (ECI) of a cluster, and $\sigma_{i}$ indicates the type of atom residing at a substitution site. Substitution sites are defined as locations in the structure which can be occupied by either $\mathrm{M}^{\prime}$ or $\mathrm{M}^{\prime \prime}$. The formation energy is defined as $E_{f}=E-(y / 2) E_{1}-(1-y / 2) E_{0}$, where $E$ is the energy per substitution site of the structure, $y$ is the variable in the $\mathrm{M}_{2-\mathrm{y}}^{\prime} \mathrm{M}_{\mathrm{y}} \mathrm{C}$ formula, and $E_{0}$ and $E_{1}$ are the per-site energies of the pure $\mathrm{M}_{2} \mathrm{C}$ and $\mathrm{M}_{2} \mathrm{C}$ structures, respectively.

MAPS optimally fits the ECI for hundreds of possible cluster combinations (sets of $\alpha \mathrm{s}$ ) in order to best reproduce the DFT-calculated data. In this way, the generated cluster expansion can quickly predict structural energies of solid solutions and find ground state configurations. We used the MAPS code to generate over 150 low-energy structures for each system, containing up to 21 atoms per cell. Fitting cluster expansions to these data achieved cross-validation scores of 2.4, 2.4, and $21.9 \mathrm{meV}$ per substitution site for the $\mathrm{Ti}_{2-\mathrm{y}} \mathrm{Nb}_{\mathrm{y}} \mathrm{C}, \mathrm{V}_{2-\mathrm{y}} \mathrm{Nb}_{\mathrm{y}} \mathrm{C}$, and $\mathrm{Ti}_{2-\mathrm{y}} \mathrm{V}_{\mathrm{y}} \mathrm{C}$ systems, respectively. These scores are analogous to the root-mean-squared error of the cluster expansion fit and are below the recommended $25 \mathrm{meV}$ per atom. ${ }^{7}$ Our nearly linear goodness-of-fit plot shows that our cluster expansion is accurate (Figure S14). Finally, the decaying ECI as a function of cluster diameter (Figure S13) indicate a well-converged cluster expansion fit. ${ }^{7}$

After generating a minimum of five stable structures for each experimentally-synthesized solid-solution percentage, we used the linearized Boltzmann transport equation as implemented in BoltzTraP2 to calculate the electrical conductivity of each stable system. ${ }^{8}$ We report the average in-plane conductivity per relaxation time $\left(\sigma_{x x} / \tau+\sigma_{y y} / \tau\right) / 2$ calculated at $300 \mathrm{~K}$. Reciprocal space $k$-point meshes from the DFT calculations were interpolated onto grids 100 times as dense. We used the electron chemical potential requisite to fulfill the charge neutrality condition at 300 $\mathrm{K}$, assuming the rigid band approximation. To simulate the random nature of the synthesized solid solutions, we calculated the conductivity at each solid-solution percentage using a weighted average, weighted by a Boltzmann factor for the thermodynamic stability of each structure. This produced an average value as well as a standard deviation, represented as an error bar on Figure 2c. Our results match previous results for single-M MXenes with surface terminations well. ${ }^{9}$

\section{S2. Solid-solution MAX phases}

For all MAX phases, conditions were determined to synthesize the precursor with no other MAX phase impurities. For example, within the Ti-Al-C system, $\mathrm{Ti}_{2} \mathrm{AlC}$ and $\mathrm{Ti}_{3} \mathrm{AlC}_{2}$ both exist, in the $\mathrm{Nb}-\mathrm{Al}-\mathrm{C}$ system $\mathrm{Nb}_{2} \mathrm{AlC}$ and $\mathrm{Nb}_{4} \mathrm{AlC}_{3}$ exist, and in the $\mathrm{V}-\mathrm{Al}-\mathrm{C}$ system, $\mathrm{V}_{2} \mathrm{AlC}$ and $\mathrm{V}_{4} \mathrm{AlC}_{3}$ exist. ${ }^{10}$ In order to properly study these interrelated solid solution systems, it is vital to ensure that only the single MAX phase is present. Furthermore, it is important that the systems produced are homogeneous, and do not have significant variability in the compositions. Because the precursor synthesis conditions affect the resultant MXene properties, conditions were determined to produce all of the interrelated MAX phase systems. ${ }^{11}$

Figure S1 shows the collected XRD patterns for all the MAX precursors used in this work. Figures S1a,d,g show the overall patterns, indicating that only $\mathrm{M}_{2} \mathrm{AX}$ compositions exist, with no 
$\mathrm{M}_{3} \mathrm{AX}_{2}, \mathrm{M}_{4} \mathrm{AX} \mathrm{X}_{3}$, or $\mathrm{M}_{5} \mathrm{AX}$ 作 phases present. Figure $\mathrm{S} 1 \mathrm{~b}$ shows the (002) peak for the $\mathrm{Ti}_{2-\mathrm{y}} \mathrm{Nb}_{\mathrm{y}} \mathrm{AlC}$, showing that the peaks shift to the left as the amount of $\mathrm{Nb}$ increases. Likewise, in Figure S1c indicates that the (110) peak shifts to the left with $\mathrm{Nb}$ content. Both trends indicate that the $a$ and $c$ lattice parameters increase with $\mathrm{Nb}$ content. For the Ti-V system, as $\mathrm{Ti}$ is increased, both the (002) and (110) peaks shift to the left (Figures S1e,f), indicating that the $a$ and $c$ lattice parameters increase with $\mathrm{Ti}$ content. Finally, the $\mathrm{V}_{2-\mathrm{y}} \mathrm{Nb}_{\mathrm{y}} \mathrm{AlC}$ experience the largest change in lattice parameters, with the (002) and (110) peaks shifting to the left with $\mathrm{Nb}$ content (Figures S1h,i). Interesting, even though the lattice parameters of $\mathrm{Nb}_{2} \mathrm{AlC}$ and $\mathrm{V}_{2} \mathrm{AlC}$ differ by $0.73 \AA(0.19 \AA)$ for the $c(a)$ lattice parameters, only a homogeneous $\mathrm{M}_{2} \mathrm{AX}$ phase is present. This illustrates the versatility of the MAX phase structure, and level of compositional control possible.

Figure S2 shows the calculated $a$ and $c$ lattice parameters for each composition. For each phase, full pattern Rietveld Refinement with GSASII. From this, the lattice parameters are directly related to the compositions linearly. Due to this direct relationship, it is vital to report the lattice parameters for all solid solution MAX phases to provide a comparison point for future studies. While there may be impurities present in the MAX precursors, the lattice parameters give direct insight into the composition and structure. Coupled with this, EDS provides another reference point.

For each of the MXene films, EDS was collected on five different spots throughout the films. Due to the light weight of C, it was not included in the comparison. For all samples, there is a slightly different ratio measured via EDS than in the initial precursor mixture (Figure S3). This can be due to impurities present, which selectively deplete one M element or because the EDS detector is not calibrated for quantitative analysis. Thus, the EDS values are used to confirm the presence and approximate ratio of both elements. For future comparison, it is recommended to utilize the MAX precursor $a$ and $c$ lattice parameters to ensure the same composition. However, it is important that both elements are present in the MXene films, implying that selective oxidation and removal of a specific $\mathrm{M}$ element is not occurring during etching or delamination. ${ }^{12}$ 


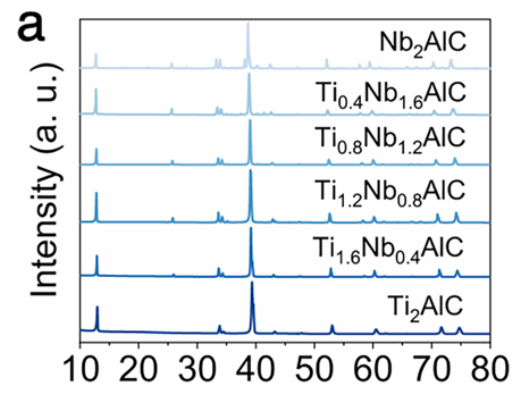

$2 \theta\left({ }^{\circ}\right)$

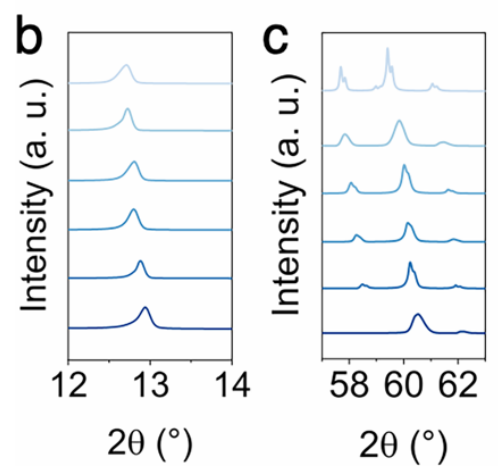

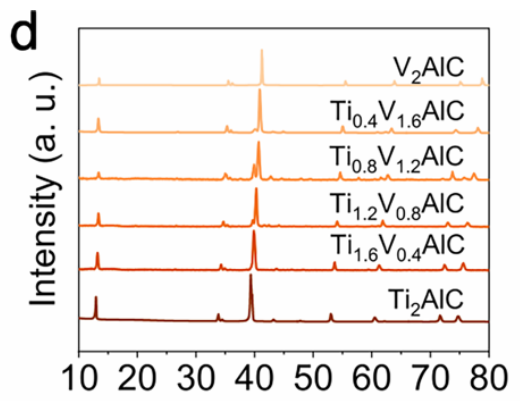

$2 \theta\left({ }^{\circ}\right)$

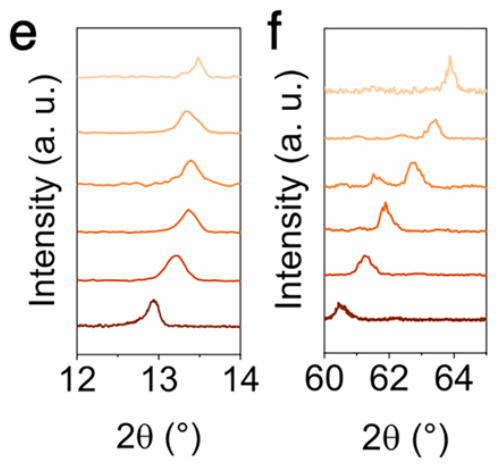

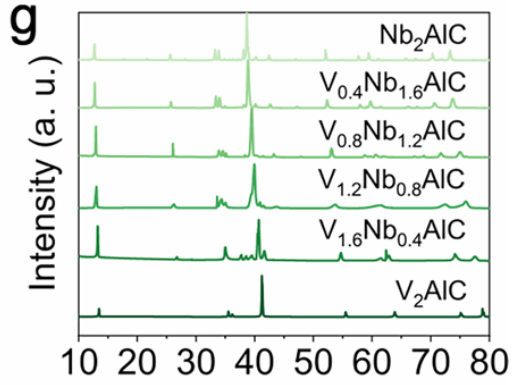

$2 \theta\left({ }^{\circ}\right)$

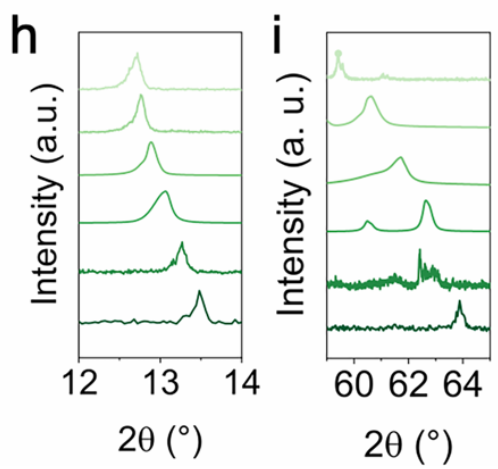

Figure S1. XRD patterns of as-synthesized solid-solution MAX phase precursors: (a) $\mathrm{Ti}_{2}$ yNbyAlC, (d) $\mathrm{Ti}_{2-\mathrm{y}} \mathrm{V}_{\mathrm{y}} \mathrm{AlC}$, and (g) $\mathrm{V}_{2-\mathrm{y}} \mathrm{Nb}_{\mathrm{y}} \mathrm{AlC}, \mathrm{y}=0,0.4,0.8,1.2,1.6$ and 2. The magnified patterns of $(\mathrm{b}, \mathrm{c}) \mathrm{Ti}_{2-\mathrm{y}} \mathrm{Nb}_{\mathrm{y}} \mathrm{AlC}$, (e, f) $\mathrm{Ti}_{2-\mathrm{y}} \mathrm{V}_{\mathrm{y}} \mathrm{AlC}$, and $(\mathrm{h}, \mathrm{i}) \mathrm{V}_{2-\mathrm{y}} \mathrm{Nb}_{\mathrm{y}} \mathrm{AlC}$. The peaks which are assigned to (002) and (110) planes shift with the changed ratios of two metal elements.
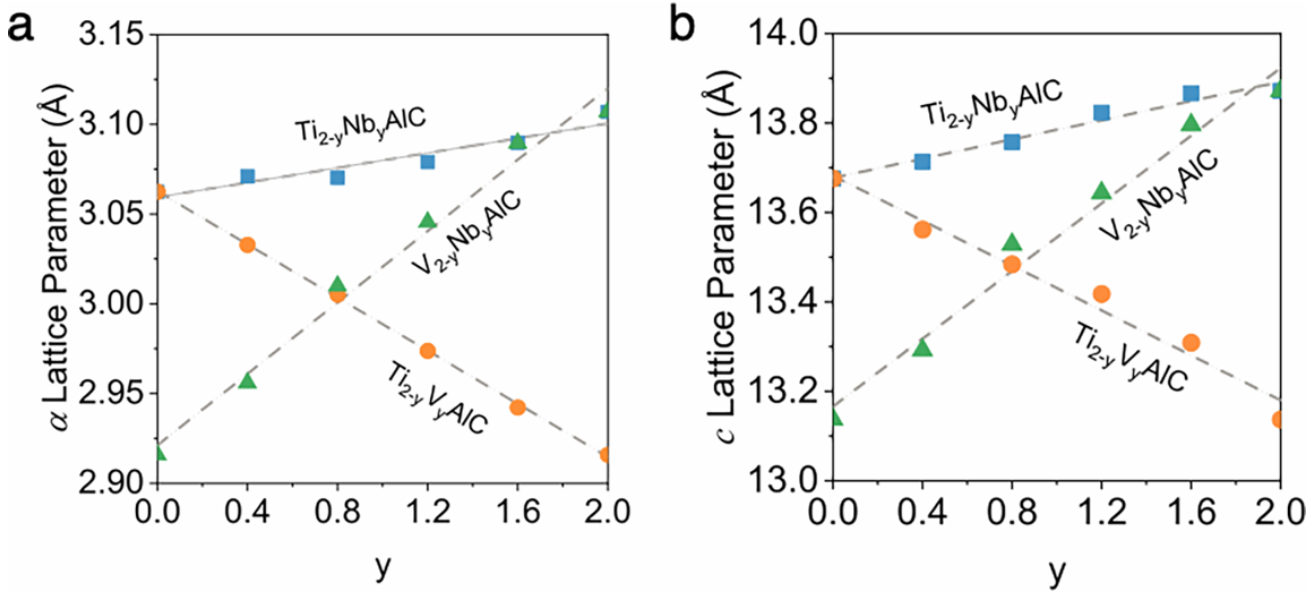

Figure S2. (a) $\alpha$ and (b) $c$ lattice parameters determined for the solid-solution MAX phase precursors of $\mathrm{Ti}_{2-\mathrm{y}} \mathrm{Nb}_{\mathrm{y}} \mathrm{AlC}, \mathrm{Ti}_{2-\mathrm{y}} \mathrm{V}_{\mathrm{y}} \mathrm{AlC}$, and $\mathrm{V}_{2-\mathrm{y}} \mathrm{Nb}_{\mathrm{y}} \mathrm{AlC}$ obtained from Rietveld Refinement, showing the linear relationship between the M-site and crystallographic lattice size. 

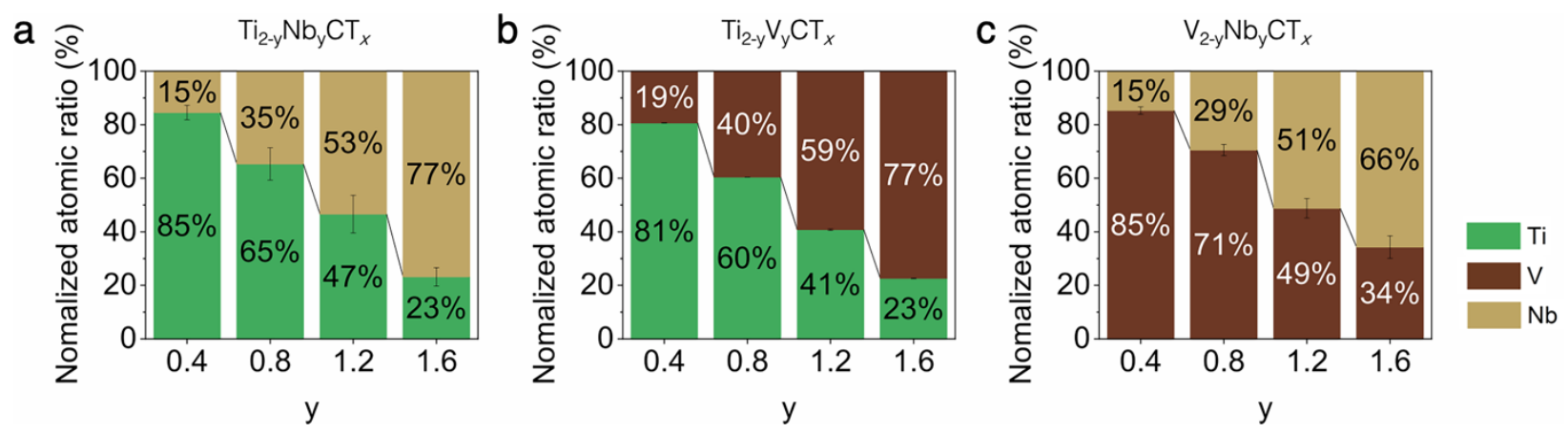

Figure S3. Normalized atomic ratios of two metal elements in solid-solution MXenes measured by EDS: (a) $\mathrm{Ti}_{2-\mathrm{y}} \mathrm{Nb}_{\mathrm{y}} \mathrm{CT}_{x}$, (b) $\mathrm{Ti}_{2-\mathrm{y}} \mathrm{V}_{\mathrm{y}} \mathrm{CT}_{x}$, and (c) $\mathrm{V}_{2-\mathrm{y}} \mathrm{Nb}_{\mathrm{y}} \mathrm{CT}_{x}$, showing the stoichiometric ratios of metal elements in solid-solution MXenes after etching and delamination.
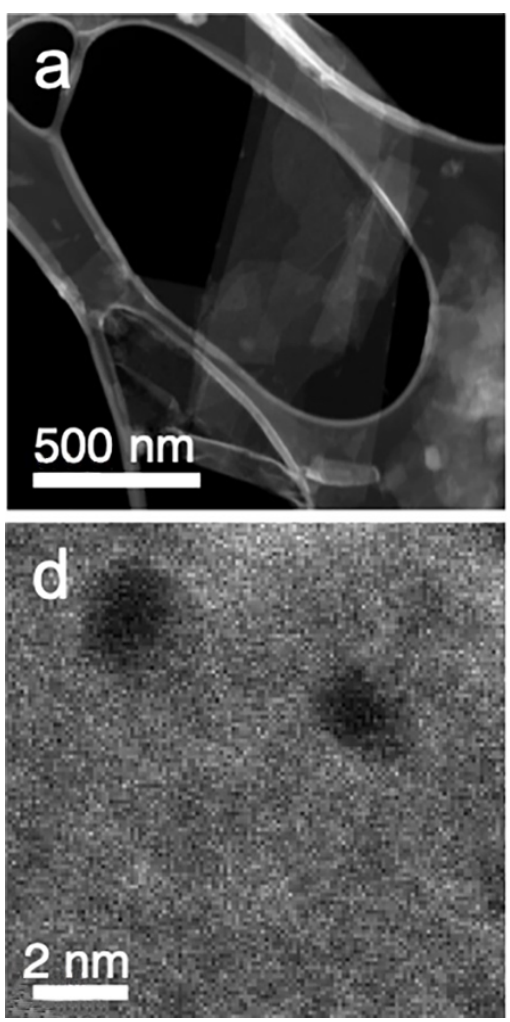
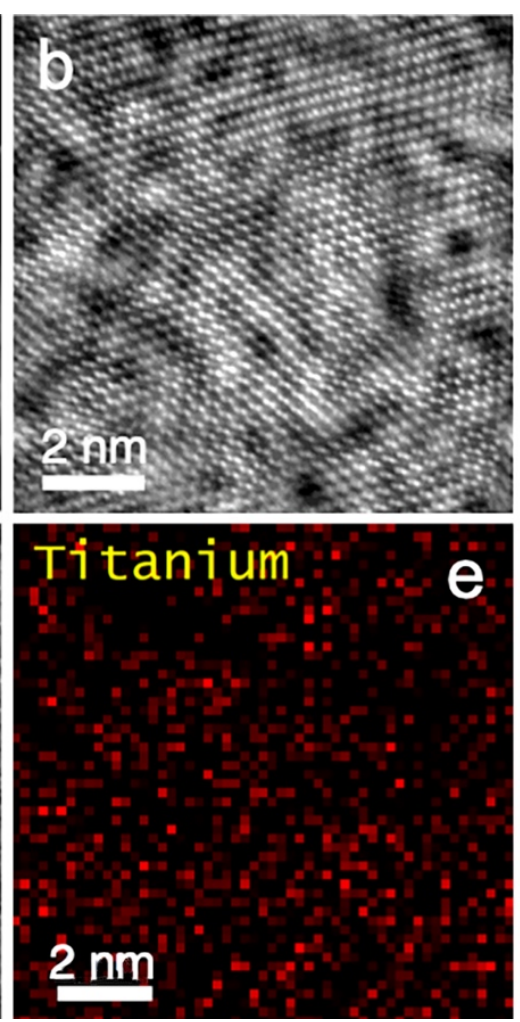
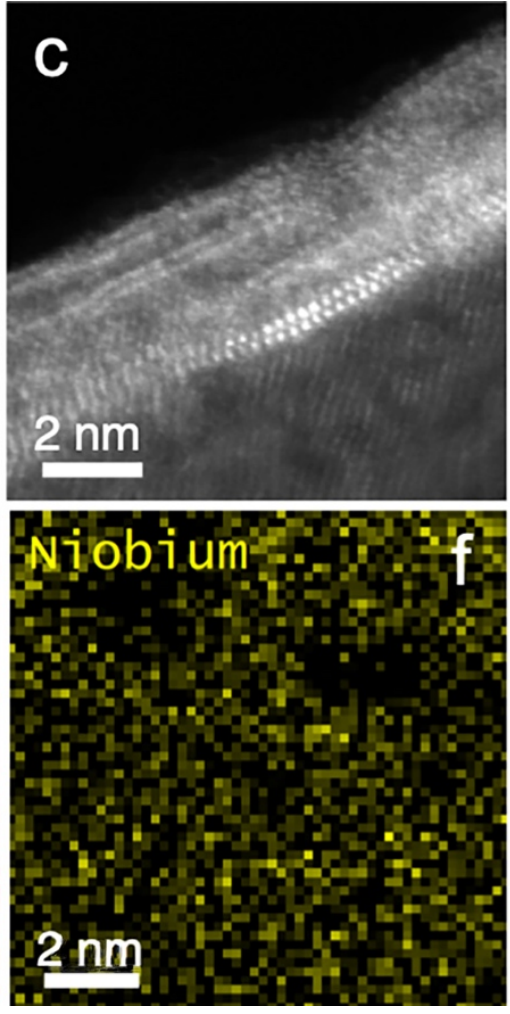

Figure S4. (a) Dark-field STEM image of $\mathrm{Ti}_{0.8} \mathrm{Nb}_{1.2} \mathrm{CT}_{x}$ MXene flake showing the typical size and shape. (b) Fourier filtered dark-field STEM image of $\mathrm{Ti}_{0.8} \mathrm{Nb}_{1.2} \mathrm{CT}_{x}$ flake along the [001] zone axis. (c) cross-sectional STEM image of $\mathrm{Ti}_{0.8} \mathrm{Nb}_{1.2} \mathrm{CT}_{x}$ flake showing the $\mathrm{M}_{2} \mathrm{C}$ structure. (d, e, f) STEM EDS mapping of $\mathrm{Ti}_{0.8} \mathrm{Nb}_{1.2} \mathrm{CT}_{x}$ MXene surface, showing the random distribution of $\mathrm{Ti}$ and $\mathrm{Nb}$. 

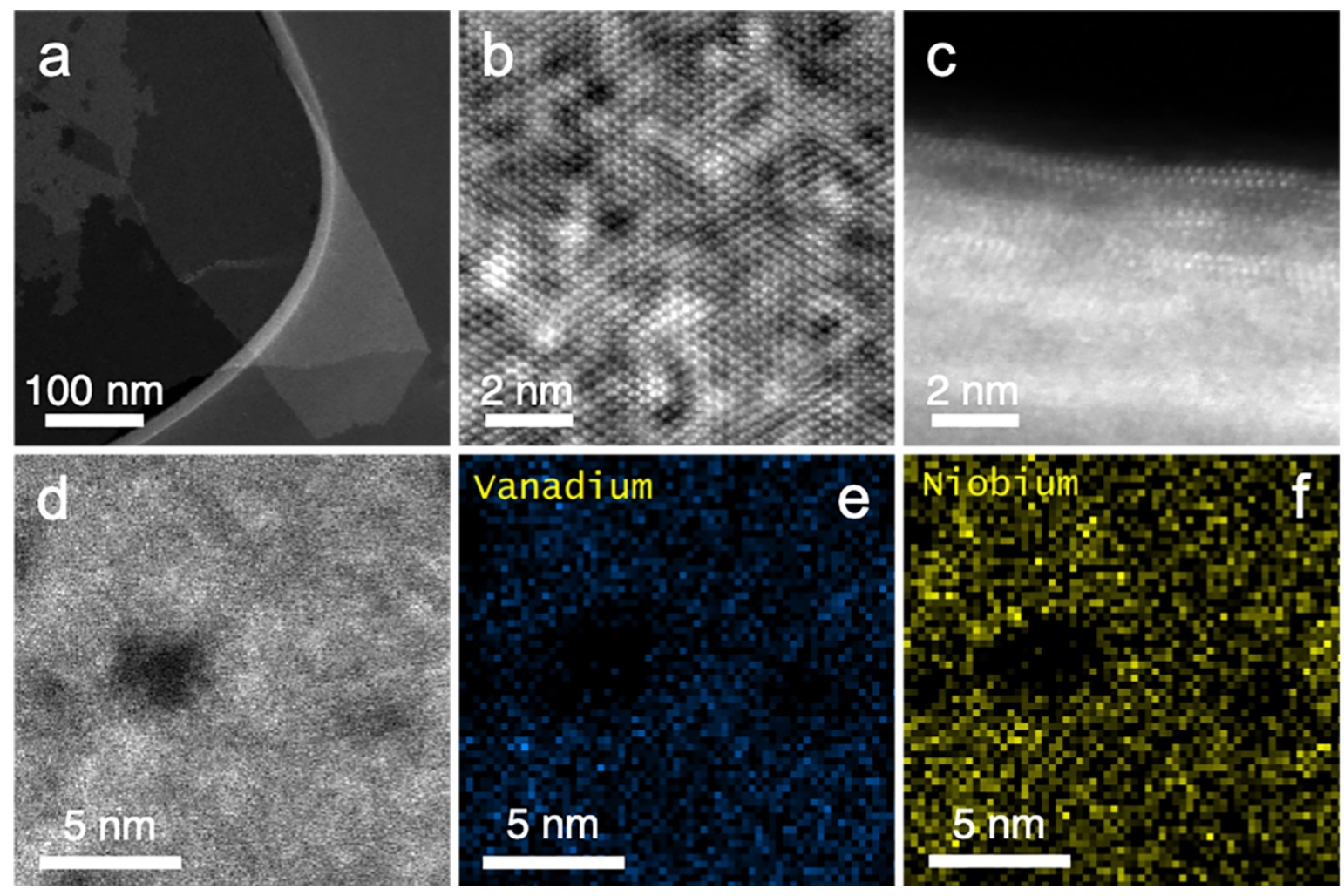

Figure S5. (a) Dark-field STEM image of $\mathrm{V}_{0.8} \mathrm{Nb}_{1.2} \mathrm{CT}_{x}$ MXene flake showing the typical size and shape. (b) Fourier filtered dark-field STEM image of $\mathrm{V}_{0.8} \mathrm{Nb}_{1.2} \mathrm{CT}_{x}$ flake along the [001] zone axis. (c) cross-sectional STEM image of $\mathrm{V}_{0.8} \mathrm{Nb}_{1.2} \mathrm{CT}_{x}$ flake showing the $\mathrm{M}_{2} \mathrm{C}$ structure. (d, e, f) STEM EDS mapping of $\mathrm{V}_{0.8} \mathrm{Nb}_{1.2} \mathrm{CT}_{x}$ MXene surface, showing the random distribution of $\mathrm{V}$ and $\mathrm{Nb}$.

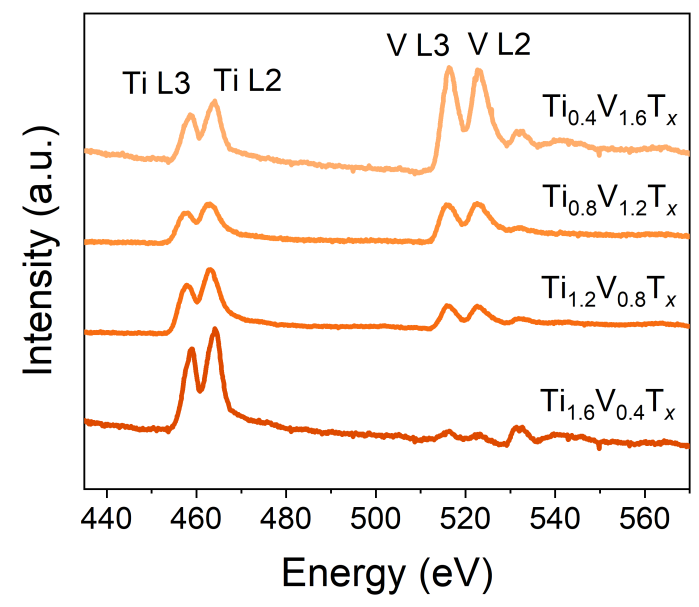

Figure S6. EELS spectra of $\mathrm{Ti}_{2-\mathrm{y}} \mathrm{V}_{\mathrm{y}} \mathrm{CT}_{x}$ MXenes. The intensities of EELS edges show the varied ratios of $\mathrm{Ti}$ to $\mathrm{V}$ with the chemical composition. 


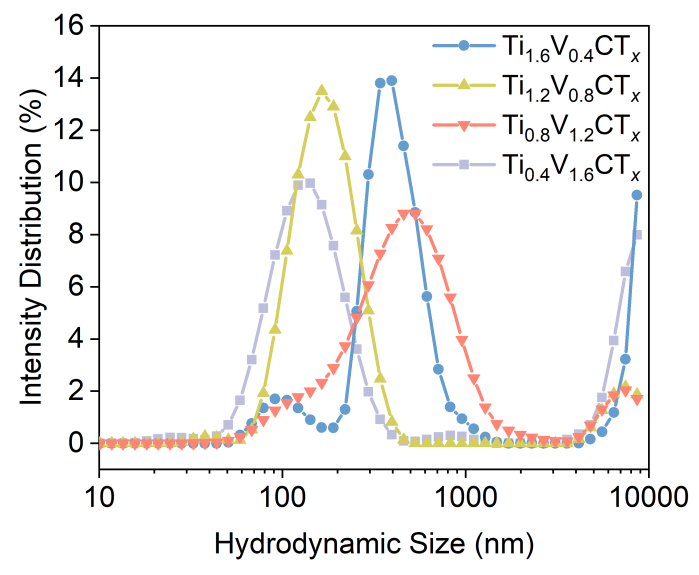

Figure S7. Dynamic light scattering (DLS) intensity distribution of $\mathrm{Ti}_{2-\mathrm{y}} \mathrm{V}_{\mathrm{y}} \mathrm{CT}_{x}$ flakes.

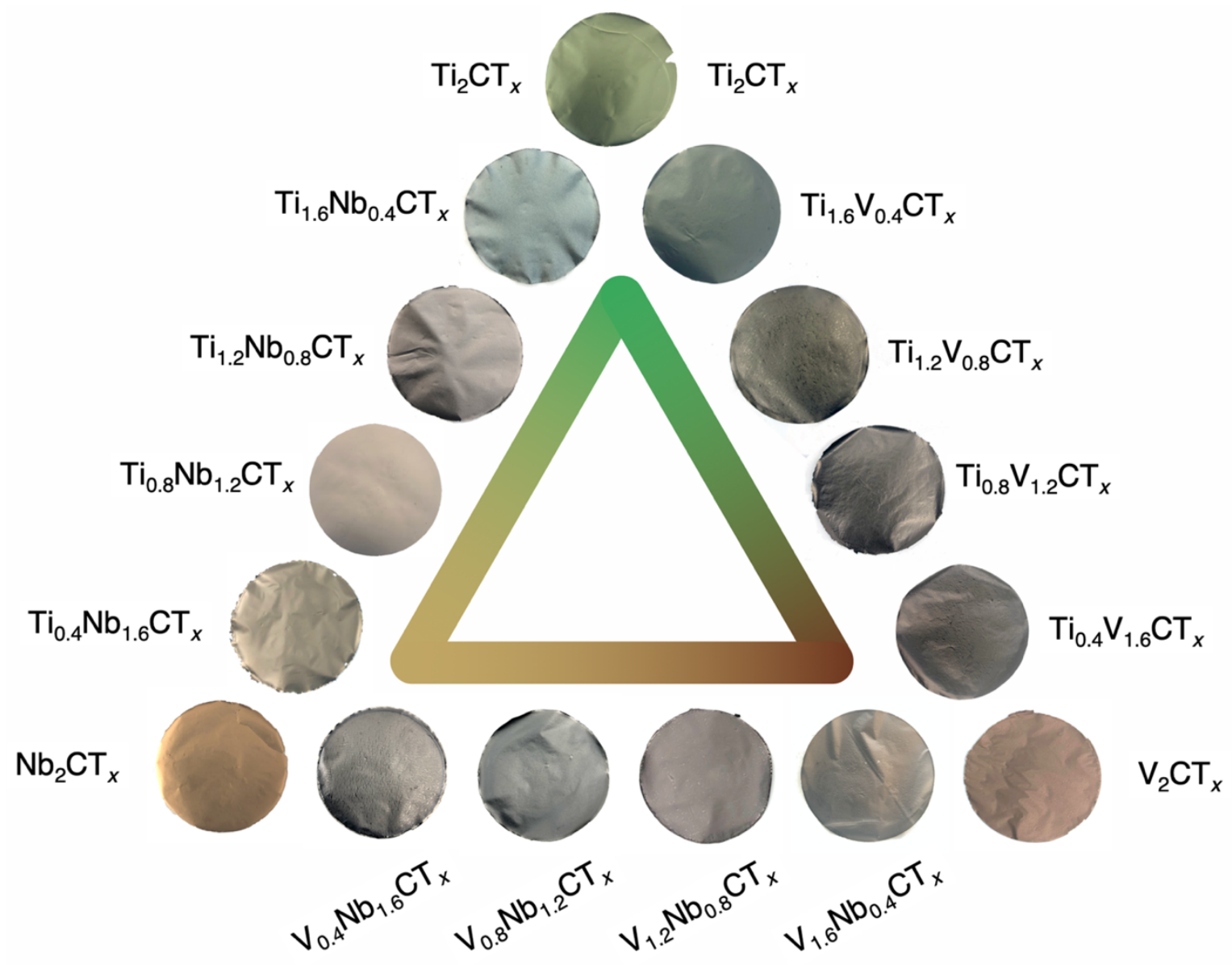

Figure S8. Digital images of freestanding solid-solution MXene films showing the color change with varied metal elements. 

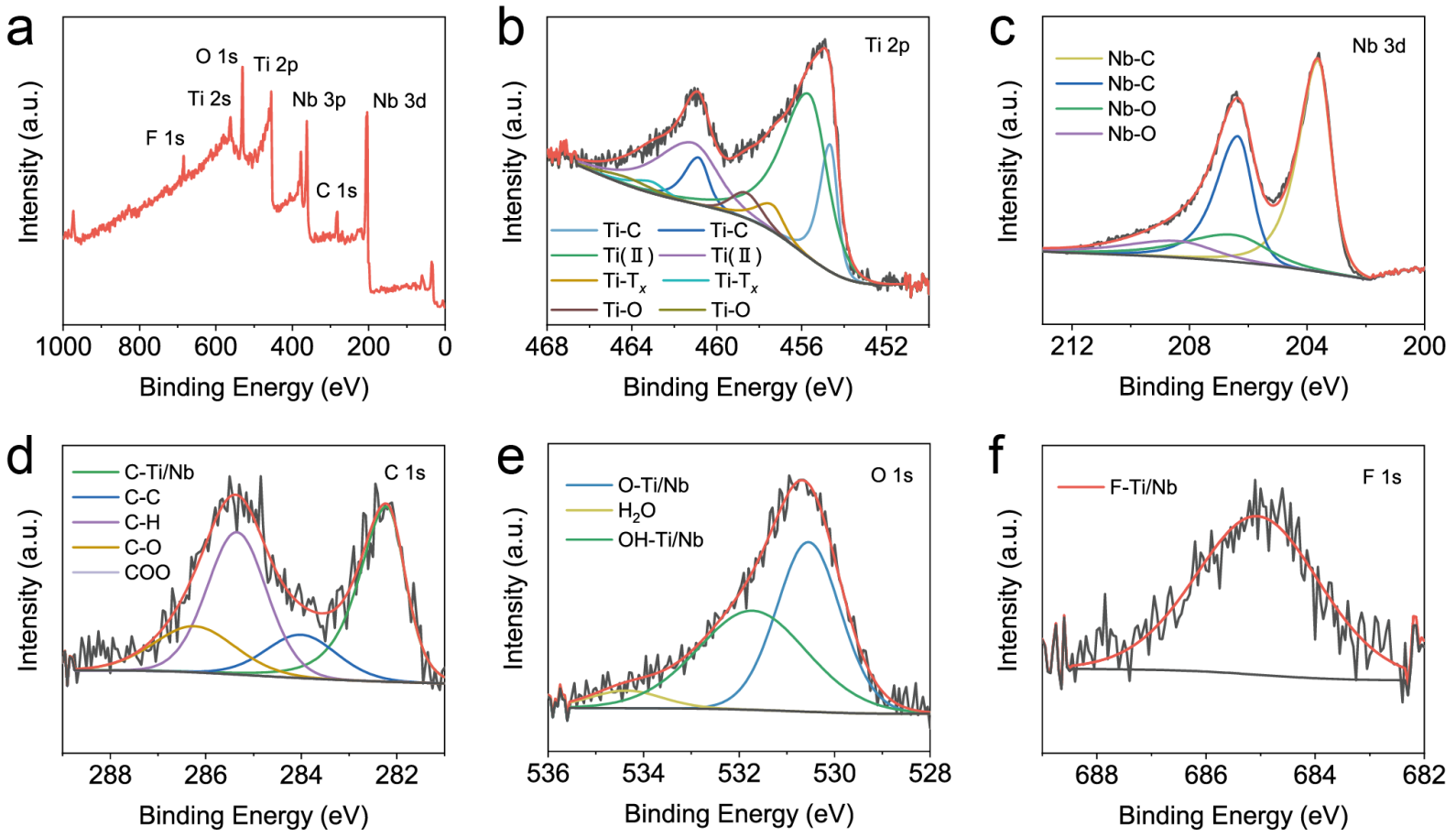

Figure S9. XPS spectra of a $\mathbf{T i}_{1.2} \mathbf{N b}_{0.8} \mathbf{C T}$ freestanding film. (a) Survey spectrum. Core level spectra of (b) Ti 2p, (c) Nb 3d, (d) C 1s, (e) O 1s, and (f) F 1s regions.
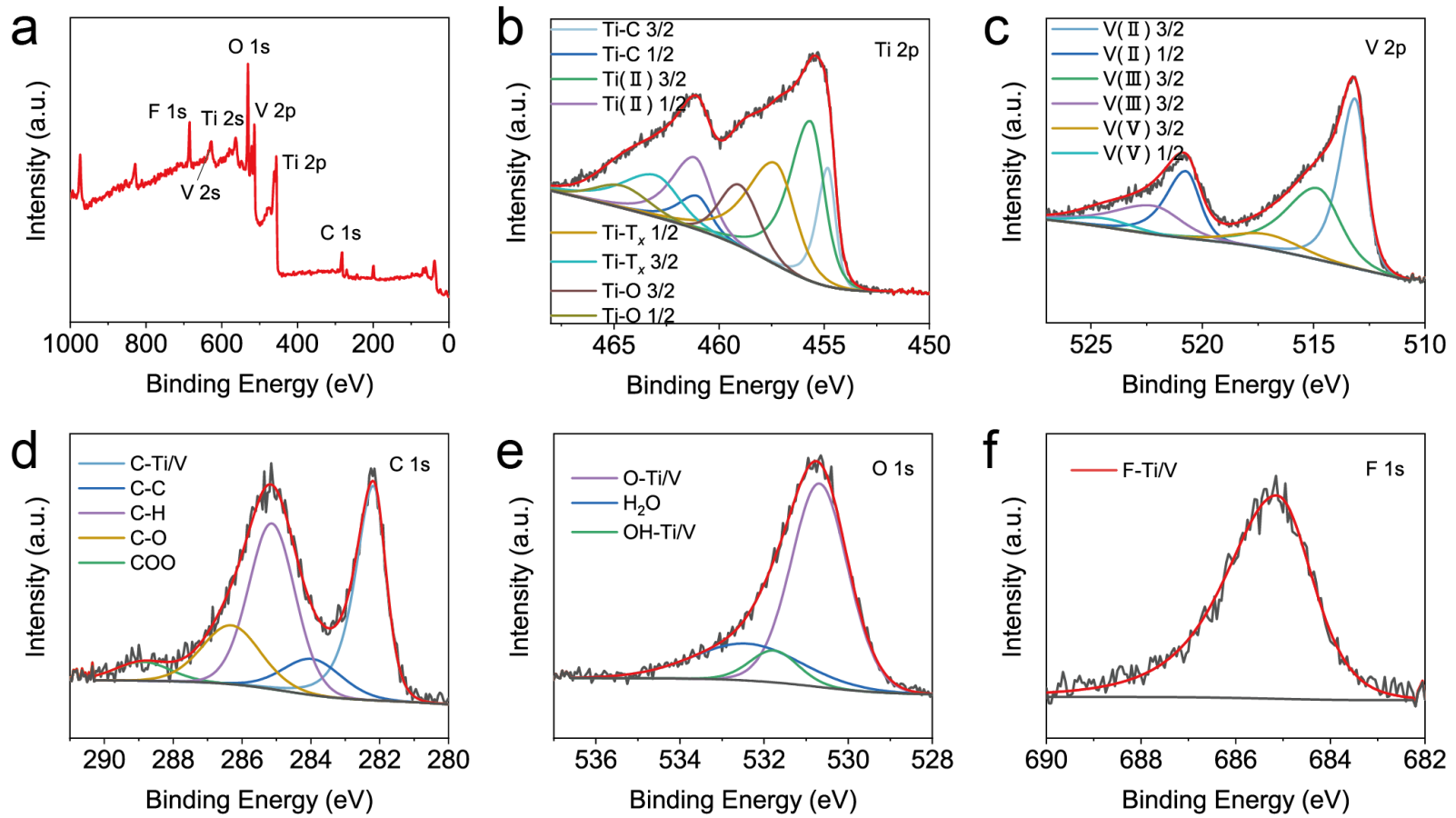

Figure S10. XPS spectra of a $\mathbf{T i}_{1.2} \mathrm{~V}_{0.8} C \mathbf{T}_{\boldsymbol{x}}$ freestanding film. (a) Survey spectrum. Core level spectra of (b) Ti 2p, (c) V 2p, (d) C 1s, (e) O 1s, and (f) F 1s regions. 

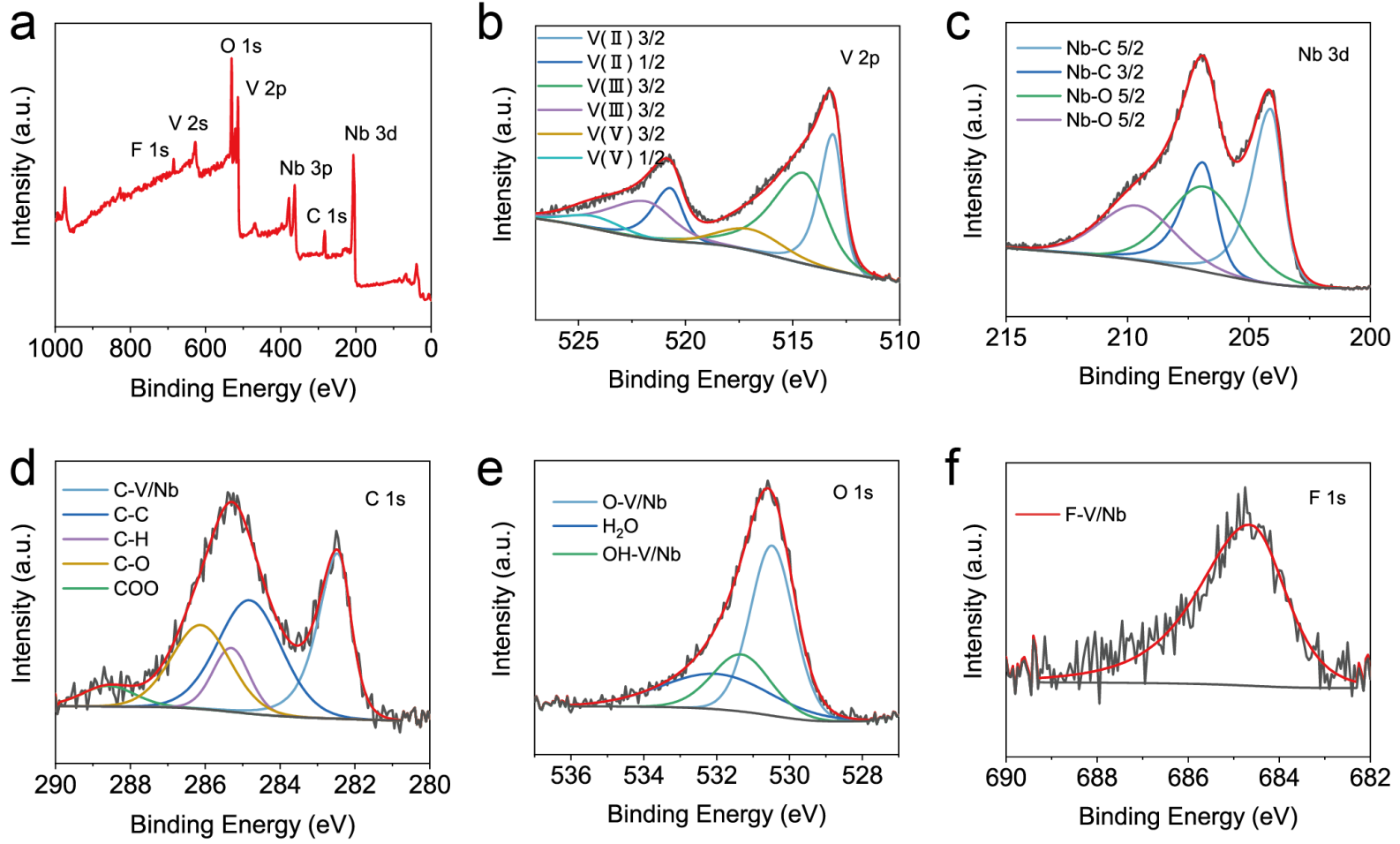

Figure S11. XPS spectra of a $\mathrm{V}_{1.2} \mathrm{Nb}_{0.8} \mathrm{CT}$ freestanding film. (a) Survey spectrum. Core level spectra of (b) V 2p, (c) Nb 3d, (d) C 1s, (e) O 1s, and (f) F 1s regions.

Table S2. The measured element amount of solid-solution $\mathrm{M}_{2-\mathrm{y}}^{\prime} \mathrm{M}_{\mathrm{y}} \mathrm{CT}_{x} \mathrm{MXenes}$ from XPS.

\begin{tabular}{|c|c|c|c|c|c|c|c|}
\hline \multirow{2}{*}{ MXene } & \multirow{2}{*}{$\mathrm{y}$} & \multicolumn{6}{|c|}{ Amount (at. \%) } \\
\hline & & $\mathrm{Ti}$ & $\mathrm{Nb}$ & $\mathrm{V}$ & $\mathrm{C}$ & $\mathrm{O}$ & $\mathrm{F}$ \\
\hline \multirow{4}{*}{ 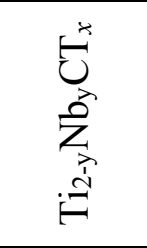 } & 0.4 & 18.46 & 5.43 & - & 12.91 & 21.18 & 6.25 \\
\hline & 0.8 & 13.70 & 11.21 & - & 12.78 & 27.67 & 6.47 \\
\hline & 1.2 & 9.78 & 15.23 & - & 16.05 & 17.29 & 4.62 \\
\hline & 1.6 & 4.51 & 14.48 & - & 12.35 & 18.77 & 11.57 \\
\hline \multirow{4}{*}{ 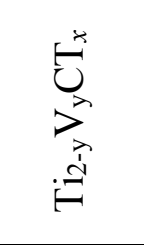 } & 0.4 & 18.93 & - & 4.84 & 12.67 & 17.2 & 9.05 \\
\hline & 0.8 & 15.35 & - & 11.05 & 9.89 & 21.22 & 9.7 \\
\hline & 1.2 & 6.51 & - & 9.24 & 5.82 & 24.55 & 18.97 \\
\hline & 1.6 & 5.92 & - & 22.19 & 12.99 & 23.95 & 8.87 \\
\hline \multirow{4}{*}{ 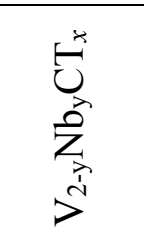 } & 0.4 & - & 3.33 & 22.28 & 11.59 & 18.49 & 6.84 \\
\hline & 0.8 & - & 5.67 & 16.94 & 9.32 & 22.79 & 4.41 \\
\hline & 1.2 & - & 8.6 & 6.07 & 11.65 & 26.63 & 3.63 \\
\hline & 1.6 & - & 13.29 & 2.31 & 11.65 & 26.42 & 1.13 \\
\hline
\end{tabular}


Table S3. Normalized stoichiometric ratios of solid-solution $\mathrm{M}_{2-\mathrm{y}} \mathrm{M}_{\mathrm{y}} \mathrm{CT}_{x} \mathrm{MXenes}$ based on the measured compositions from XPS.

\begin{tabular}{|c|c|c|c|c|c|c|c|}
\hline \multirow{2}{*}{ MXene } & \multirow{2}{*}{$\mathrm{y}$} & \multicolumn{6}{|c|}{ Stoichiometric ratio } \\
\hline & & $\mathrm{Ti}$ & $\mathrm{Nb}$ & $\mathrm{V}$ & $\mathrm{C}$ & $\mathrm{O}$ & $\mathrm{F}$ \\
\hline \multirow{4}{*}{ 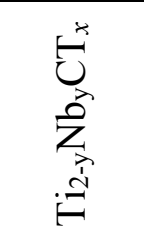 } & 0.4 & $1.6^{*}$ & 0.47 & - & 1.12 & 1.84 & 0.54 \\
\hline & 0.8 & $1.2 *$ & 0.98 & - & 1.12 & 2.42 & 0.57 \\
\hline & 1.2 & 0.77 & $1.2 *$ & - & 1.26 & 1.36 & 0.36 \\
\hline & 1.6 & 0.49 & $1.6^{*}$ & - & 1.36 & 2.07 & 1.28 \\
\hline \multirow{4}{*}{ 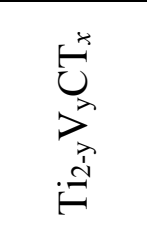 } & 0.4 & $1.6^{*}$ & - & 0.41 & 1.07 & 1.45 & 0.76 \\
\hline & 0.8 & $1.2 *$ & - & 0.86 & 0.77 & 1.66 & 0.76 \\
\hline & 1.2 & 0.85 & - & $1.2 *$ & 0.76 & 3.19 & 2.56 \\
\hline & 1.6 & 0.43 & - & $1.6^{*}$ & 0.94 & 1.73 & 0.64 \\
\hline \multirow{4}{*}{ 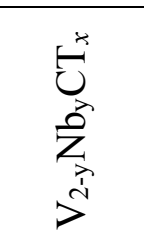 } & 0.4 & - & 0.24 & $1.6^{*}$ & 0.83 & 1.33 & 0.49 \\
\hline & 0.8 & - & 0.4 & $1.2^{*}$ & 0.66 & 1.61 & 0.31 \\
\hline & 1.2 & - & $1.2 *$ & 0.85 & 1.63 & 3.72 & 0.51 \\
\hline & 1.6 & - & $1.6^{*}$ & 0.28 & 1.4 & 3.18 & 0.13 \\
\hline
\end{tabular}

*The theoretical value was used for normalization.

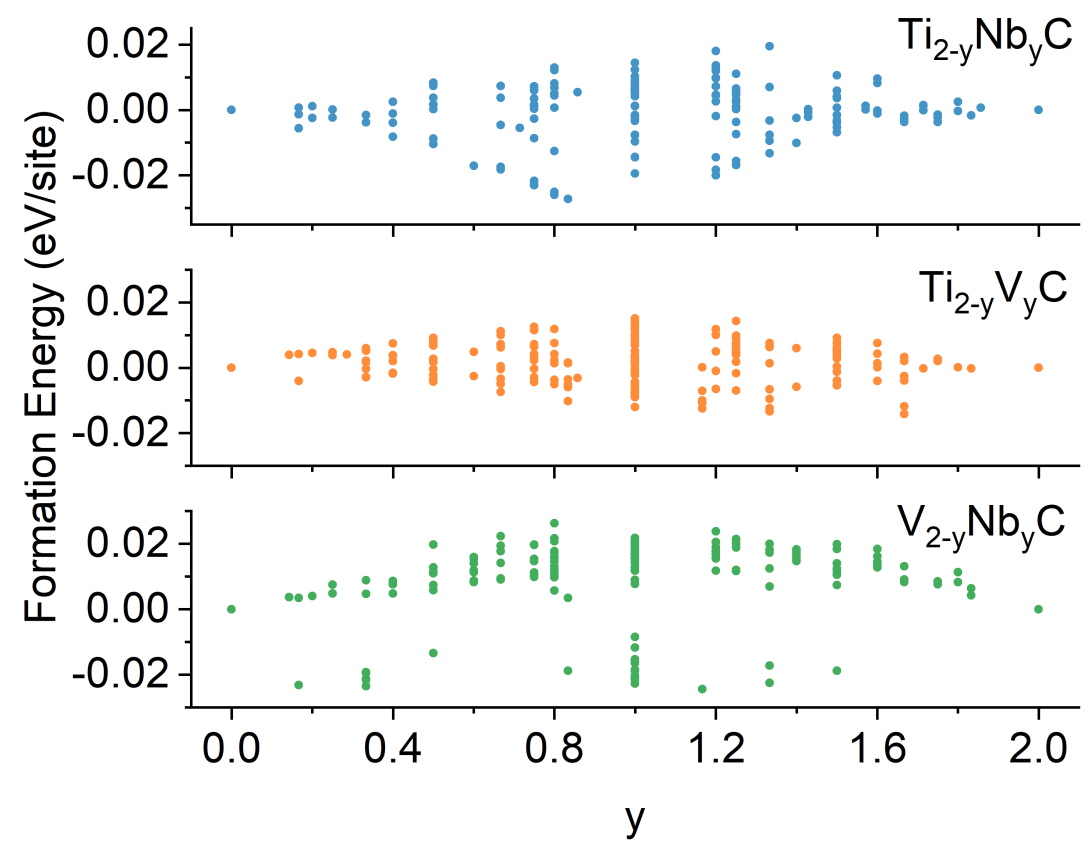

Figure S12. Formation energies for solid solutions of the three $\mathrm{M}_{2-y}^{\prime} \mathrm{M}_{\mathrm{y}} \mathrm{C}$ MXene systems, calculated by DFT. We weight each solid-solution structure by a Boltzmann factor including its formation energy when determining the overall conductivity at each solid-solution percentage. 


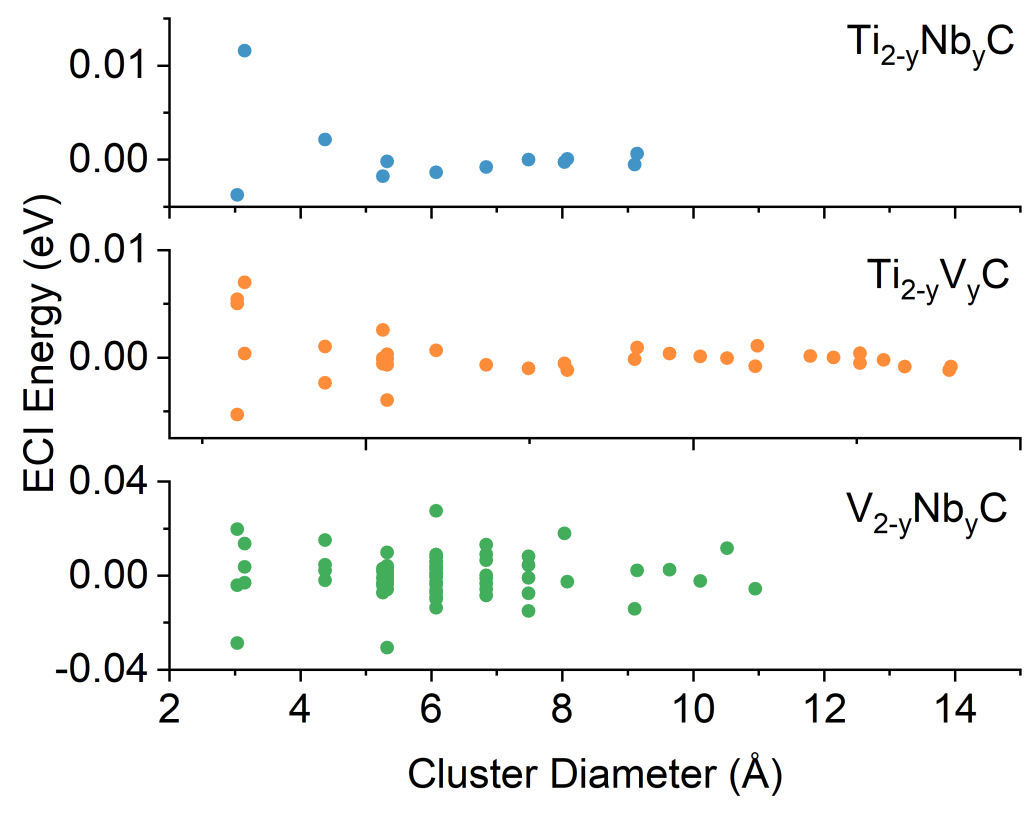

Figure S13. Effective cluster interaction (ECI) energies for the cluster expansions of the three $\mathrm{M}_{2-}$ ${ }_{\mathrm{y}} \mathrm{M}{ }_{\mathrm{y}} \mathrm{C} \mathrm{MXene}$ systems. The decay of ECI towards zero as a function of cluster diameter indicates a well-converged cluster expansion. Further, the strong positive ECI at low diameter indicates a preference for homogeneous elemental distribution.

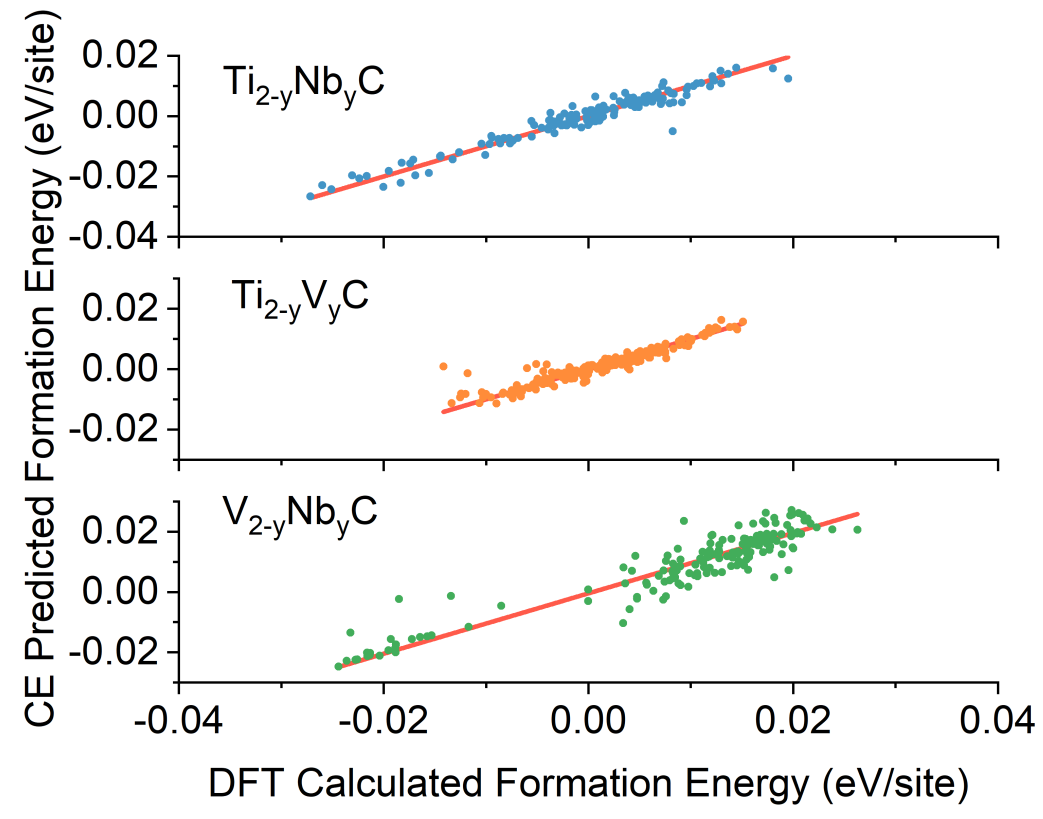

Figure S14. Goodness-of-fit plots for the three $\mathrm{M}_{2-\mathrm{y}} \mathrm{M}_{\mathrm{y}}{ }_{\mathrm{C}} \mathrm{C} \mathrm{MXene}$ systems. The straight line represents a linear fit. The root mean-squared error values for the $\mathrm{Ti}_{2-\mathrm{y}} \mathrm{V}_{\mathrm{y}} \mathrm{C}, \mathrm{Ti}_{2-\mathrm{y}} \mathrm{Nb}_{\mathrm{y}} \mathrm{C}$, and $\mathrm{V}_{2 \text { - }}$ ${ }_{\mathrm{y}} \mathrm{Nb}_{\mathrm{y}} \mathrm{C}$ systems is $0.0023,0.0021$, and $0.0046 \mathrm{eV}$ per site, indicating a good fit for the cluster expansions. 
a

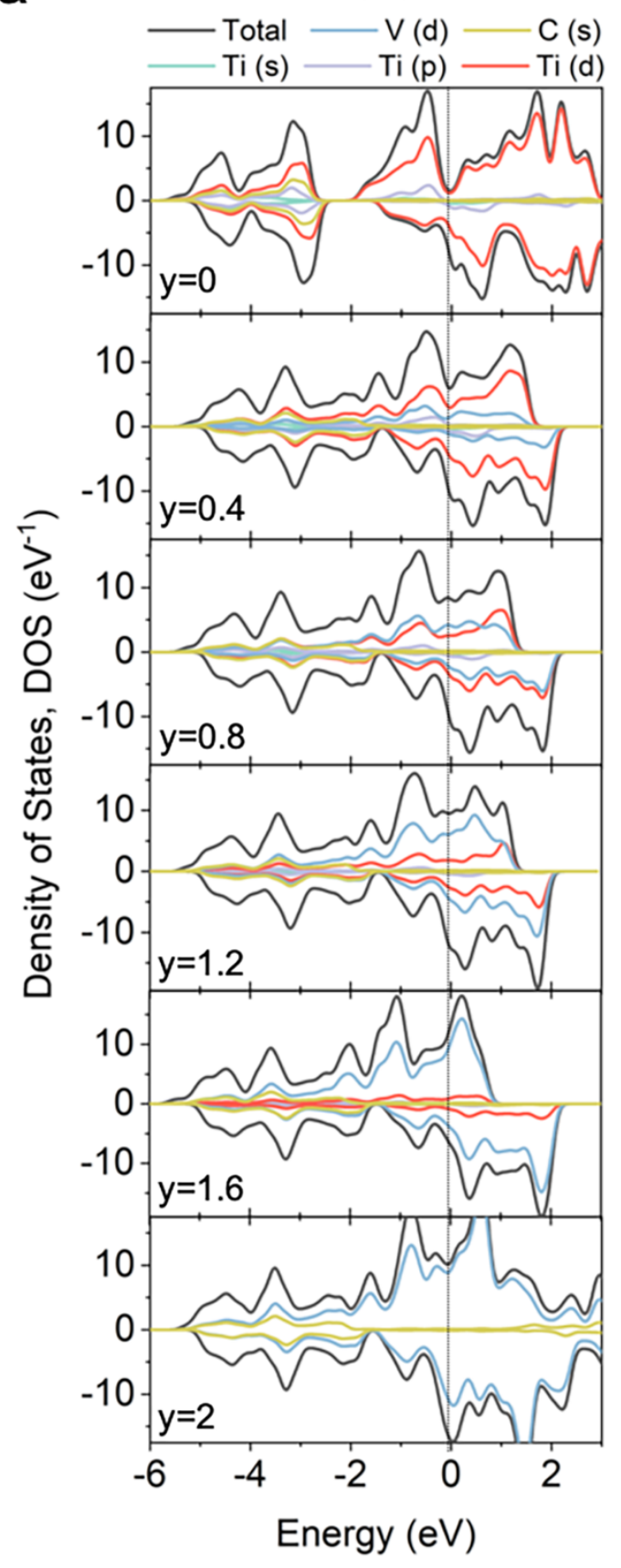

b

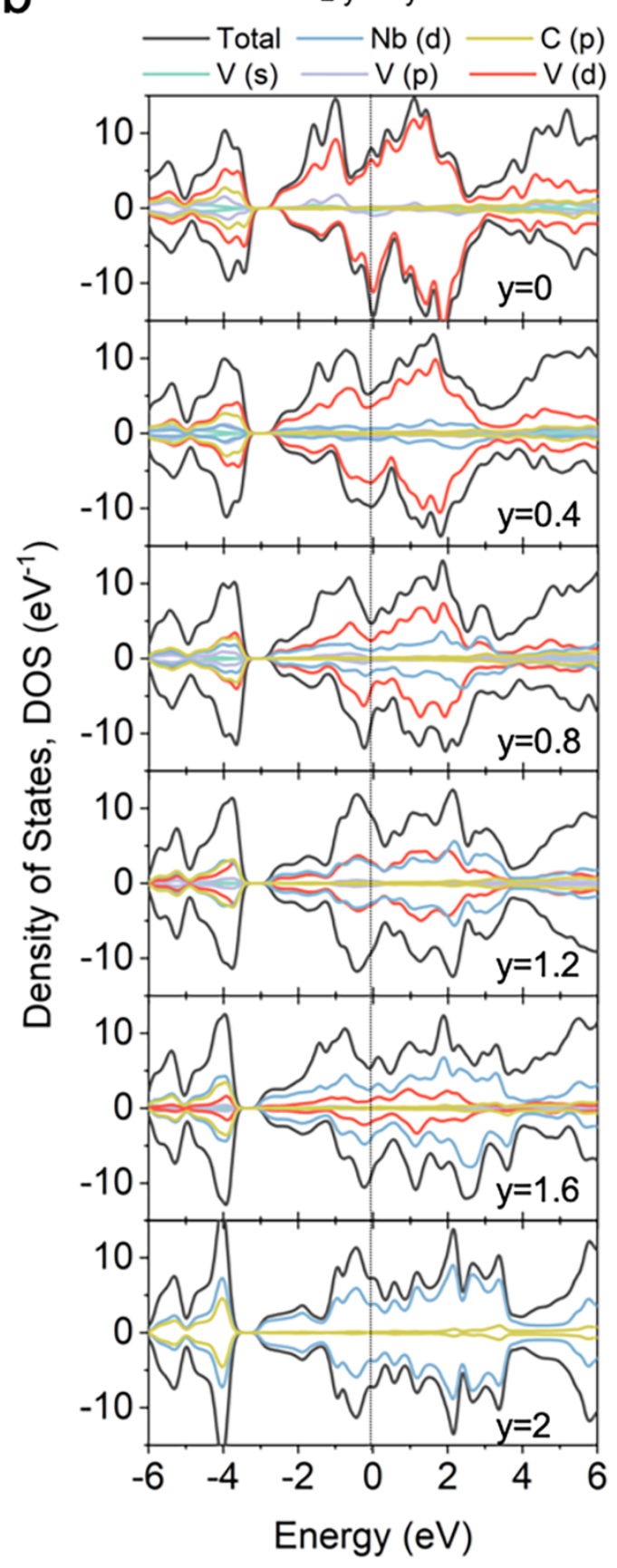

Figure S15. The computed electron density of states (DOS) of bare (a) $\mathrm{Ti}_{2-\mathrm{y}} \mathrm{V}_{\mathrm{y}} \mathrm{C}$ and (b) $\mathrm{V}_{2-}$ ${ }_{y} \mathrm{Nb}_{\mathrm{y}} \mathrm{C}$ MXenes, showing the DOS change with solid-solution composition. 

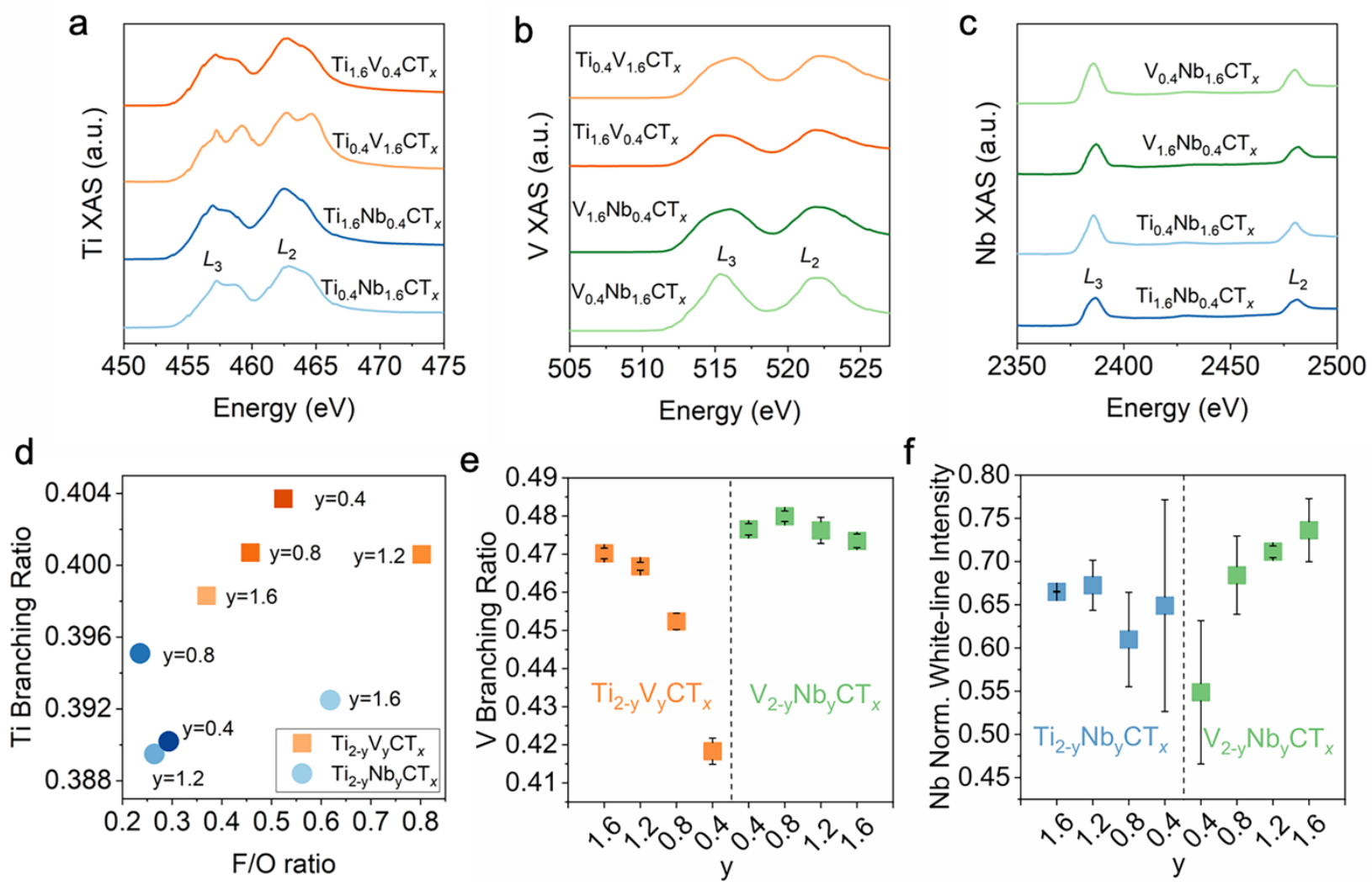

Figure S16. XAS analysis of solid-solution MXenes. Selected XAS spectra of the solid-solution MXenes: (a) Ti, (b) $\mathrm{V}$, and (c) $\mathrm{Nb}$. (d) Dependence of the Ti branching ratio on the measured $\mathrm{F} / \mathrm{O}$ ratio for both $\mathrm{Ti}_{2-\mathrm{y}} \mathrm{V}_{\mathrm{y}} \mathrm{CT} \mathrm{T}_{x}$ and $\mathrm{Ti}_{2-\mathrm{y}} \mathrm{Nb}_{\mathrm{y}} \mathrm{CT} \mathrm{T}_{x}$ MXenes. (e) $\mathrm{V}$ branching ratio of $\mathrm{Ti}_{2-\mathrm{y}} \mathrm{V}_{\mathrm{y}} \mathrm{CT}_{x}$ and $\mathrm{Ti}_{2-}$ ${ }_{y} \mathrm{Nb}_{\mathrm{y}} \mathrm{CT}_{x}$ MXenes. (f) $\mathrm{Nb}$ normalized white-line intensity of $\mathrm{Ti}_{2-\mathrm{y}} \mathrm{Nb}_{\mathrm{y}} \mathrm{CT}_{x}$ and $\mathrm{V}_{2-\mathrm{y}} \mathrm{Nb}_{\mathrm{y}} \mathrm{CT}_{x}$ MXenes which is defined as total integral of $L_{3}$ and $L_{2}$ divided by the continuum intensity ${ }^{13}$; error bars indicate standard deviation of measurements taken at different parts of the same samples.
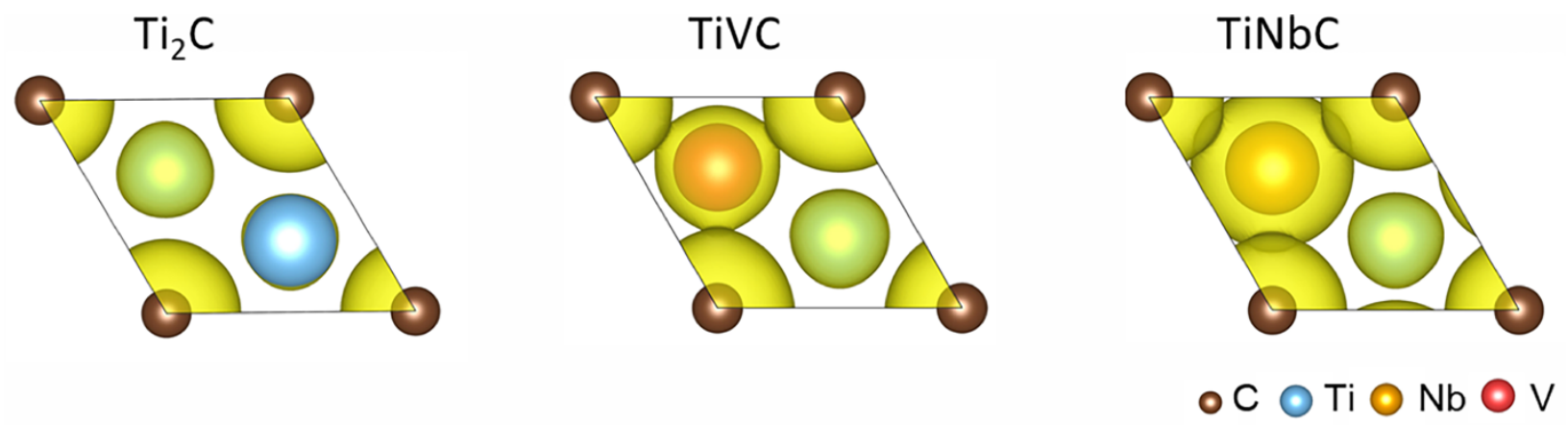

Figure S17. Constant electron density isosurfaces at 0.08 electrons per cubic Angstrom for $\mathrm{Ti}_{2} \mathrm{C}$, $\mathrm{TiVC}$, and $\mathrm{TiNbC}$ ground state structures. Adding $\mathrm{V}$ increases the electron density from the $\mathrm{Ti}_{2} \mathrm{C}$ case, while adding $\mathrm{Nb}$ increases it further. 


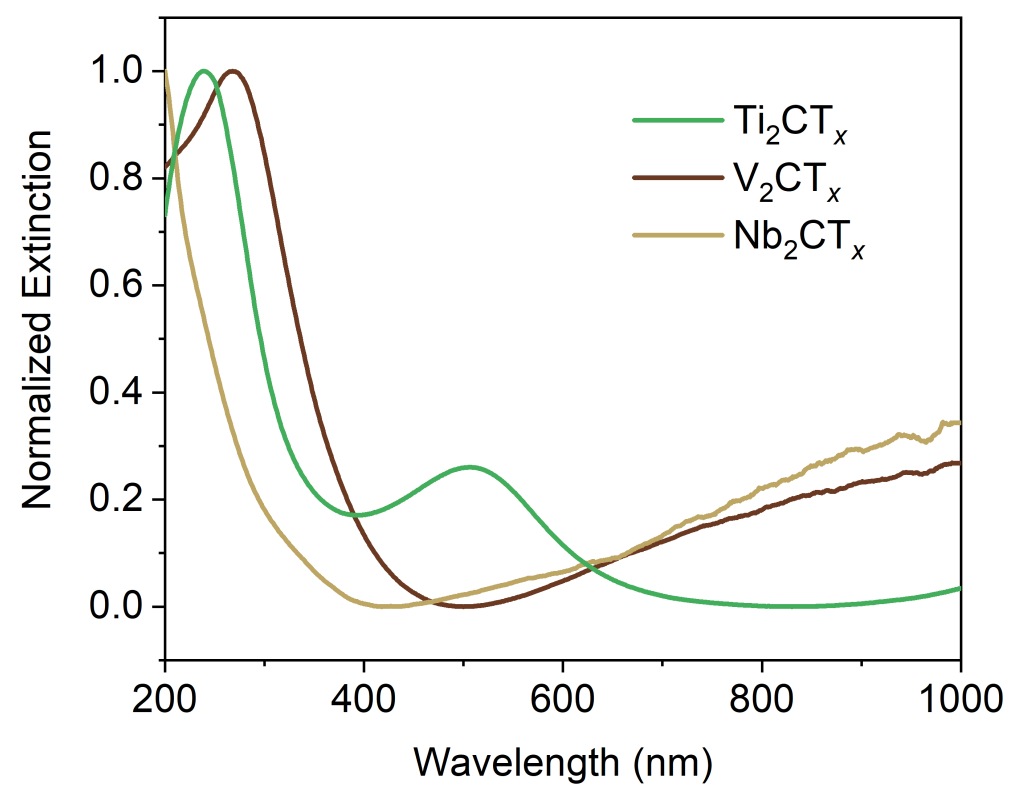

Figure S18. Normalized UV-vis spectra of $\mathrm{M}_{2} \mathrm{CT}_{x}$ MXenes $\left(\mathrm{Ti}_{2} \mathrm{CT}_{x}, \mathrm{~V}_{2} \mathrm{CT}_{x}\right.$, and $\left.\mathrm{Nb}_{2} \mathrm{CT}_{x}\right)$.

Table S4. Calculated electrical conductivities of $\mathrm{O}$ - and $\mathrm{F}$-terminated MXenes. These results show that the general trend of increasing conductivity with increasing number and delocalization of valence electrons holds for bare as well as terminated MXenes.

\begin{tabular}{cc}
\hline MXene & $\sigma / \tau * 10^{18}\left[\Omega \mathrm{cm} \mathrm{s}^{-1}\right.$ \\
\hline $\mathrm{Ti}_{2} \mathrm{CO}_{2}$ & 0.003 \\
$\mathrm{~V}_{2} \mathrm{CO}_{2}$ & 1.112 \\
$\mathrm{Nb}_{2} \mathrm{CO}_{2}$ & 3.076 \\
$\mathrm{Ti}_{2} \mathrm{CF}_{2}$ & 4.782 \\
$\mathrm{~V}_{2} \mathrm{CF}_{2}$ & 6.182 \\
$\mathrm{Nb}_{2} \mathrm{CF}_{2}$ & 11.618 \\
\hline
\end{tabular}


Table S5. The parent crystal structure used for cluster expansion, in .cif format. This structure was used to generate solid solutions in the MAPS cluster expansion code. Solid solutions were geometrically relaxed in order to find the overall structural energy of formation.

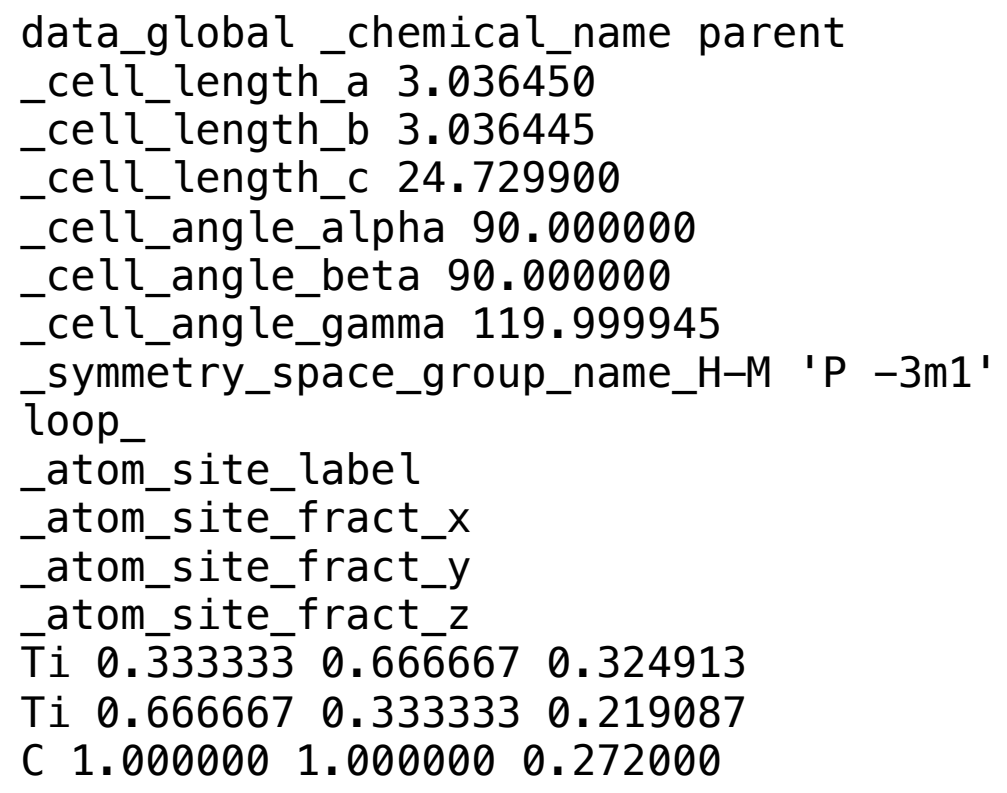

\section{References}

1. Toby, B. H.; Von Dreele, R. B., GSAS-II: the Genesis of a Modern Open-Source All Purpose Crystallography Software Package. J. Appl. Crystallogr. 2013, 46, 544-549.

2. Kohn, W.; Sham, L. J., Self-Consistent Equations Including Exchange and Correlation Effects. Phys. Rev. 1965, 140, A1133.

3. Kresse, G.; Furthmüller, J., Efficiency of Ab-Initio Total Energy Calculations for Metals and Semiconductors Using a Plane-Wave Basis Set. Comput. Mater. Sci. 1996, 6, 15-50.

4. Kresse, G.; Furthmüller, J., Efficient Iterative Schemes for Ab Initio Total-Energy Calculations Using a Plane-Wave Basis Set. Phys. Rev. B 1996, 54, 11169.

5. Perdew, J. P.; Burke, K.; Ernzerhof, M., Generalized Gradient Approximation Made Simple. Phys. Rev. Lett. 1996, 77, 3865.

6. Blöchl, P. E., Projector Augmented-Wave Method. Phys. Rev. B 1994, 50, 17953.

7. Van De Walle, A.; Asta, M.; Ceder, G., The Alloy Theoretic Automated Toolkit: A User Guide. 2002, arXiv preprint: cond-mat/0212159.

8. Madsen, G. K.; Carrete, J.; Verstraete, M. J., BoltzTraP2, a Program for Interpolating Band Structures and Calculating Semi-Classical Transport Coefficients. Comput. Phys. Commun. 2018, $231,140-145$.

9. Khazaei, M.; Arai, M.; Sasaki, T.; Estili, M.; Sakka, Y., Two-Dimensional Molybdenum Carbides: Potential Thermoelectric Materials of the MXene Family. Phys. Chem. Chem. Phys. 2014, 16, 7841-7849.

10. Sokol, M.; Natu, V.; Kota, S.; Barsoum, M. W., On the Chemical Diversity of the MAX Phases. Trends Chem. 2019, 1, 210-223. 
11. Shuck, C. E.; Han, M.; Maleski, K.; Hantanasirisakul, K.; Kim, S. J.; Choi, J.; Reil, W. E.; Gogotsi, Y., Effect of $\mathrm{Ti}_{3} \mathrm{AlC}_{2}$ MAX Phase on Structure and Properties of Resultant $\mathrm{Ti}_{3} \mathrm{C}_{2} \mathrm{~T}_{x}$ MXene. ACS Appl. Nano Mater. 2019, 2 (6), 3368-3376.

12. Ahmed, B.; Ghazaly, A. E.; Rosen, J., $i$-MXenes for Energy Storage and Catalysis. $A d v$. Funct. Mater. 2020, 2000894.

13. Bach, D.; Schneider, R.; Gerthsen, D.; Verbeeck, J.; Sigle, W., EELS of niobium and stoichiometric niobium-oxide phases-Part I: Plasmon and near-edges fine structure. Microsc. Microanal. 2009, 15 (6), 505-523. 